\title{
Evaluation of Effects of Increasing Molar Substitution of Hydroxypropylene on Physicochemical, Functional and Morphological Properties of Starch from Water Yam (Dioscorea Alata)
}

\author{
Gibson Lucky Arueya ${ }^{1} \&$ Adenike Abiola Ojesanmi ${ }^{1}$ \\ ${ }^{1}$ Department of Food Technology, University of Ibadan, Nigeria \\ Correspondence: Gibson Lucky Arueya, Department of Food Technology, University of Ibadan, Nigeria. Tel: \\ 234-805-954-6297. E-mail: arueyagibson@yahoo.com
}

Received: May 14, 2019

Accepted: May 31, 2019 Online Published: June 25, 2019

doi:10.5539/jfr.v8n4p58

URL: https://doi.org/10.5539/jfr.v8n4p58

\begin{abstract}
Amidst rising demand for modified starch, hydroxypropylated derivatives from water yam, an underutilized tropical botanical source remains unexplored. The objective of this work therefore is to extract starch from water yam, modify same by hydroxypropylation and determine their physicochemical, functional and morphological characteristics.

Extraction of starch was carried out by blending peeled water yam previously soaked in $0.2 \%(\mathrm{w} / \mathrm{v}) \mathrm{NaHSO}_{3}$ solution and filtering the resulting slurry. The filterate was next suspended in $0.2 \% \mathrm{NaOH}$ solution, allowed to sediment and the supernatant oven-dried $\left(40^{\circ} \mathrm{C}\right)$ for $24 \mathrm{hrs}$. The dried product was subjected to hydroxypropylation (HP) (propylene oxide 4-12\%/100g starch) and extent of molar substitution (MS) determined. The native and Hydroxypropylated starch (HPS) were evaluated for physicochemical, functional and morphological characteristics following standard methods. Pasting properties were analysed using Rapid Visco Analyzer (RVA) and elucidation of inherent functional groups was carried out by analyzing the FTIR Spectrum.

Starch yield of $84.2 \%$ (dry wt. basis) and molar substitution (0.0024-0.05) of HPS were established. Bulk density increased $\left(0.4988-0.6005 \mathrm{~g} / \mathrm{cm}^{3}\right)$ with MS. There was significant $(\mathrm{p}=0.05)$ increase in the degree of Whiteness $(\mathrm{W})$ (42.4-63.6\%). Although granule size reduction was evident $(33.88-33.43 \mu \mathrm{m})$, hydroxypropylation did not affect their morphology. There was decline in concentrations of crude protein $(0.18-0.01 \%)$, ash $(1.35-0.34 \%)$ and amylose (44.19-37.48\%) as MS rose. In contrast, there was significant $(\mathrm{p}=0.05)$ increase in water $(1.76-2.66 \mathrm{~g} / \mathrm{g})$ and oil absorption capacities $(0.72-1.42 \mathrm{~g} / \mathrm{g})$, swelling power $(1.54-4.19 \mathrm{~g} / \mathrm{g})$ and solubility $(3.17-5.84 \mathrm{~g} / \mathrm{g})$ at $50^{\circ} \mathrm{C}$. Freeze thaw cycles showed marked reduction in syneresis (10.3-1.09\%) as MS increased. Peak Viscosity, pasting temperature and peak time of the HPS ranges were 297.83-583.6, 81.9-86. $4^{\circ} \mathrm{C}$, and $4.5-7.0$ mins respectively. FTIR band spectra indicated the presence of hydroxypropyl substituent groups in the modified starch.

Hydroxypropylated starch (from water yam) at different molar substitution has been characterised and its properties established with strong potentials for wider applications in food systems.
\end{abstract}

Keywords: water yam starch, hydroxypropylation, propylene oxide, molar substitution

\section{Introduction}

Traditional sources of starch are no longer sustainable because the current industrial demand for starch is being met only by limited number of crops essentially corn, potato, wheat and tapioca (Ellis et al., 1998). The world starch market including their modified variants is thus dominated by starches from these sources. With increasing industrial demand for starches, there is need to explore new and alternative sources of starch. Tropical root and tuber crops such as water yam (Dioscorea alata) could offer this opportunity as they are rich in starch (Hoover, 2001, Wickramasinghe, 2009).

Water yam is grown widely in tropical and subtropical regions of the world. They are plants yielding tubers with a starch concentration of between 70 and $80 \%$ of dry matter. D. alata in particular is known for its high nutritional content (Zhang \& Oates, 1999), variable shapes, the majority of which are cylindrical. The flesh of the tuber varies in color shades from white to purple (FAO, 1994).Also, the texture of its flesh is not as firm as 
that of white yam and so finds far less preference in the preparation of 'pounded yam'- a popular delicacy of West Africans. Interestingly, this yam species exhibits high yield(calorific energy and protein three times more superior), multiplication ratio and better tuber storability when compared to the preferred indigenous 'English white guinea yam'(Dioscorea rotundata). Water yam (Dioscorea alata) has an added advantage for sustainable cultivation and comes in handy, especially when yam production seems to be on the decline owing to high production costs, low yields and post-harvest losses. In spite of the aforementioned beneficial characteristics, water yam seems underutilized when compared to the other varieties of yam ostensibly because it is perceived as food for the poor, playing a minor role in international trade.

In a bid to enhance the competitiveness of these potential starch sources, considerable works have been conducted on their physicochemical, functional and pasting properties as well as on their modified variants. For instance, Water yam (Dioscorea alata) starch was modified through alkaline and alcoholic-alkaline treatments. The results obtained showed that water absorption capacity (swelling) and solubility increased, freeze-thaw stability improved with each treatment, while a lower tendency to setback became evident (Dalahaye, 2009). Annealed purple water yam showed that annealing decreased peak viscosity, final viscosity but improved peak time (Mojiono et al., 2012). Falade \& Ayetigbo, (2015) also reported the effects of annealing, acid hydrolysis and citric acid modifications on physical and functional properties of starches from four yams (Dioscorea alata inclusive).The result further indicated that while starch granule sizes reduced significantly with the modifications, the annealed starch showed a better foam stability than citric modified and acid hydrolysed yam starches.

There are quite a number of previous works on hydroxypropylation of other starch sources. Hydroxypropyl derivative of pigeon pea revealed that swelling and solubility increased with molar substitution, syneresis reduced after hydroxypropylation, while increased starch paste clarity and peak viscosity were evident along with a drop in pasting temperature (Lawal, 2008).Another report on hydroxypropylation of white yam by Lawal, (2008) confirmed that hydroxypropylation enhanced the free swelling capacity (FSC), solubility, but reduced setback and retrogradation.

Wattanachant et al., (2001) also reported that through hydroxypropylation involving a significant increase in molar substitution, paste clarity decreased, swelling power and solubility rose compared to that of the native starch. Majzoobi et al., (2014) compared the characteristics of hydroxypropylated wheat starch with that of oat and found out that hydroxypropylation did not change the morphological features of oat starch while it had some effect on granular structure of wheat. Senanayake et al., (2014) reported that hydroxypropylated sweet potato starch gels did not show syneresis for two weeks. Hydroxypropyl derivatives from native lima and jack bean starches showed increased viscosity progressively with molar substitution (MS), as well as improved swelling power,solubility and pasting parameters (Oladebeye et al.,2013). Hydroxypropylated starch of yellow millet showed the presence of slight fragmentation and a distinct groove in their central core region and increase in breakdown and setback viscosities (Olayinka et al., 2015). Notably, no study on effect of hydroxypropylation modification on physico-chemical properties of native water yam (Dioscorea alata,) starch at various degree of substitution have been carried out, hence the need for this work.

It is instructive to note that many industries in developing countries like Nigeria have relied on imported maize and wheat starches for use in various applications. This importation has led to loss of large amounts of foreign currency and employment opportunities for Nigerians. Though demand for starch is ever increasing, food industries in third world countries like Nigeria often contend with challenges of increased costs, supply capacity, availability and late deliveries. There is a need therefore, to explore indigenous crops locally grown by subsistence farmers, as alternative sources of starch as well as its modified variant. Previous attempts have so far focused on cassava. Water yam just like cassava, has great potential for this purpose, yet their utilization in diversified forms has been very limited due to lack of information on its functional and morphological properties. A detailed knowledge of the characteristics of the starch would facilitate its utilization in industries; enable tailoring of the properties by chemical modification to specific applications and bringing economic benefit in the long run.

\section{Materials and Methods}

\subsection{Isolation and Purification of Starch}

Fresh tubers of water yam (Dioscorea alata, Dagidagi) were obtained from International Institute of Tropical Agriculture (IITA), Ibadan, Oyo state, Nigeria. All reagents used in this work were of analytical grade. Starch was extracted by the method of Walter et al., (2000) with slight modifications. The Freshly harvested yam tubers were peeled and homogenized using a Warring commercial blender. The mixture was filtered through double layered muslin cloth, and dispersed in $0.2 \% \mathrm{NaOH}$ solution, the starch allowed to sediment and the supernatant 
decanted. The washing with distilled water continued until a clear supernatant was obtained. Starch cakes were spread thinly on the tray and oven dried at $40^{\circ} \mathrm{C}$ for $24 \mathrm{hrs}$.

\subsection{Hydroxypropylation}

The method of Kaur et al., (2004) was used with modifications. Water yam starch (100 g) was weighed using $500 \mathrm{ml}$ screw cap jars and distilled water $(200 \mathrm{ml})$ was added followed by the addition of $20 \mathrm{~g}$ of $\mathrm{Na}_{2} \mathrm{SO}_{4}$. The slurry was mixed for $30 \mathrm{~min}$ and the $\mathrm{pH}$ adjusted to 10.5 with $1 \mathrm{M} \mathrm{NaOH}$. Propylene oxide $(4,6,8,10$ and $12 \mathrm{ml})$ was added and the suspension was thoroughly mixed. The reaction was maintained at $40^{\circ} \mathrm{C}$ in a shaking incubator for $24 \mathrm{~h}$. The starch suspensions were neutralized with dilute $\mathrm{HCl}(0.1 \mathrm{M})$ and the $\mathrm{pH}$ was adjusted to 5.0. The slurry was centrifuged for $15 \mathrm{~min}$ at $10,000 \mathrm{rpm}$. The resulting starch cakes were washed with distilled water several times and oven dried at $40^{\circ} \mathrm{C}$.

\subsection{Determination of Molar Substitution of Hydroxypropylated Starch}

Additives was used for the determination of the hydroxypropyl groups. Starch samples (100 mg) were weighed into a $100-\mathrm{ml}$ volumetric flask and sulphuric acid $(25 \mathrm{ml} ; 0.5 \mathrm{M})$ added. The mixture was digested in a boiling water bath until a clear solution was obtained. The resulting clear solution was cooled and made up to $100 \mathrm{ml}$ with distilled water. An aliquot of the solution $(1 \mathrm{ml})$ were pipetted into $25-\mathrm{ml}$ graduated test tubes, immersed in cold water and $8 \mathrm{ml}$ of concentrated sulphuric acid was added drop wise to the tube. After thorough shaking, the tubes were placed in boiling water bath for $20 \mathrm{~min}$. The tubes were next allowed to air-cool and thereafter placed in ice bath until the solution was chilled. Ninhydrin reagent (3\% Ninhydrin in $5 \% \mathrm{Na}_{2} \mathrm{~S}_{2} \mathrm{O}_{5}, 0.6 \mathrm{ml}$ ) was added and the tubes well shaken before placing in $25^{\circ} \mathrm{C}$ water bath for $1 \mathrm{~h}$. The solutions were next made up to $25 \mathrm{ml}$ with concentrated sulphuric acid and thoroughly mixed. It was then transferred to $1-\mathrm{cm}$ cells, and after 10 min, the absorbance was measured at $590 \mathrm{~nm}$ with the starch blank used as reference. A calibration curve was prepared with an aliquot $(1 \mathrm{ml})$ of standard aqueous solutions, containing 10, 20, 30, 40 and $50 \mathrm{mg}$ of propylene glycol per ml. The propylene glycol concentration in the starch was calculated from the standard curve, converted to equivalent hydroxypropyl groups from each molar solution using the following equation:

$$
\mathrm{MS}=\frac{162 \mathrm{~W}}{100-(\mathrm{M}-1) \mathrm{W}}
$$

where MS, molar substitution; W, equivalent hydroxypropyl group in $100 \mathrm{~g}$ of starch and $\mathrm{M}$, molecular weight of $\mathrm{C}_{3} \mathrm{H}_{6} \mathrm{O}$.

\subsection{Physicochemical Properties}

\subsubsection{Loose and Tapped Bulk Densities}

Two grams of the powdered sample was placed in a 10 millilitres measuring cylinder and the volume $\left(\mathrm{V}_{0}\right)$ occupied by the sample without tapping was noted. After 100 taps on the table, the filled volume $\left(\mathrm{V}_{100}\right)$ was read. The bulk loose and tapped densities were calculated as the ratio of weight to volume $\left(\mathrm{V}_{0}\right.$ and $\mathrm{V}_{100}$, respectively). (Emeje et al., 2012).

\subsubsection{Powder Flowability of the Starches}

The flowability of the starches was determined using the Carr index and Hausner ratio (Falade \& Ayetigbo, 2015). Loose and packed bulk densities provided information on the flowability of powders. These values are used to calculate the Carr index which is a measure of the flowability and compressibility of the starches. According to Falade \& Ayetigbo (2015), values (\%) of 5 to 10, 12 to 16, 18 to 21, and 23 to 28 represent excellent, good, fair and poor flow properties, respectively.

The Carr index and Hausner ratio were calculated as follows:

Carr index $(\%)=100$ (packed bulk density-loose bulk density)/loose bulk density

Hausner ratio $=$ packed bulk density $\div$ loose bulk density

\subsubsection{Colour Evaluation of Native and Hydroxypropylated Starches}

The Commission Internationale de l'Eclairage (CIE) $\mathrm{L}^{*}, \mathrm{a}^{*}$ and $\mathrm{b}^{*}$ parameters was determined using a colourimeter (Chromameter CR 410 Konica Minolta, Sensing inc., Japan) having optical sensor lens at $2^{\circ}$ observer (Gonnet, 1999). The instrument was calibrated with a standard white tile $\left(L^{*}=93.75, a^{*}=-5.36, b^{*}=\right.$ 8.50). Multiple measurements of $\mathrm{L}^{*}, \mathrm{a}^{*}$ and $\mathrm{b}^{*}$ parameters was determined using the colourimeter on the samples. From the data obtained, deltachroma $(\Delta \mathrm{C})$, colour intensity $(\Delta \mathrm{E})$, hue angle $\left(\mathrm{H}^{*}\right)$, and degree of whiteness $(\% \mathrm{~W})$ was calculated according to the equations $1,2,3$ and 4 , respectively shown below (Gonnet, 1999). 


$$
\begin{gathered}
\Delta \mathrm{C}=\left(\Delta \mathrm{a}^{* 2}+\Delta \mathrm{b}^{* 2}\right)^{0.5} \\
\Delta \mathrm{E}=\left(\Delta \mathrm{L}^{* 2}+\Delta \mathrm{a}^{* 2}+\Delta \mathrm{b}^{* 2}\right)^{0.5} \\
\mathrm{H}^{*}=\tan ^{-1}\left(\mathrm{~b}^{* / \mathrm{a}^{*}}\right) \\
\mathrm{W}(\%)=100-\left[\left(100-\mathrm{L}^{*}\right)^{2}+\left(\left(\mathrm{a}^{*}\right)^{2}+\left(\mathrm{b}^{*}\right)^{2}\right)\right]^{0.5} .
\end{gathered}
$$

Colour measurement of both native and hydroxypropylated starches were taken using the standard white tile as reference $\left(L^{*}=93.75, a^{*}=-5.36, b^{*}=8.50\right)$

\subsubsection{Microscopic Examination of the Native and Hydroxypropylated Derivatives of Water Yam Starch}

The size and shape of starch granules were obtained from extracted yam starch samples. A small amount of starch powder was scooped with a spatula onto a clean micro-slide $(75 \times 25 \mathrm{~mm})$. A drop of distilled water was added and distributed thinly on the slide and covered with a slip. Starch granules were observed under a light microscope (LEICA CME, Leica Microsystems) and sizes were determined by measuring the granule diameter with an ocular micrometer fixed to the lens of the microscope. The actual sizes of the granules were calculated by multiplying their mean diameters by a factor of $2.47 \mu \mathrm{m}$ (i. e. the factor for objective magnification that was used) which was calculated earlier using the parallax obtained between a stage micrometer (Graticules Ltd, Tonbridge, England) and the calibrations of the eye piece.. A minimum of 100 granules were selected randomly and measured for each sample. Observation was done under x 400 magnification. (AOAC, 2000)

\subsection{Chemical Properties}

2.5.1 pH, Moisture, Ash, Protein, Crude fibre, Crude fat and Total Carbohydrate (Nitrogen free Extract, NFE) were Determined According To Standard Methods(AOAC,2000)

\subsubsection{Amylose and Amylopectin}

Amylose content was determined in duplicates using the method of Hoover \& Ratnayake (2002). Approximately $0.1 \mathrm{~g}(100 \mathrm{mg})$ of the starch sample was weighed into a $100 \mathrm{ml}$ volumetric flask and $1 \mathrm{ml}$ of $99.7-100 \%(\mathrm{v} / \mathrm{v})$ ethanol and $9 \mathrm{ml}$ of $1 \mathrm{M} \mathrm{NaOH}$ was carefully added and the mouth of the flask was covered with foil and the content mixed well. The sample was heated for 10 minutes in a boiling water bath to gelatinize the starch. The sample was then removed from the water bath and allowed to cool to ambient temperature. It was then filled to mark with distilled water and shaken thoroughly. About $5 \mathrm{ml}$ of the mixture was then pipetted into another 100 $\mathrm{ml}$ volumetric flask. Acetic acid $(1 \mathrm{~N}, 1 \mathrm{ml})$ and $2 \mathrm{ml}$ of iodine solution were added, topped to mark with distilled water and shaken thoroughly, while ensuring that the flask is wrapped in aluminium foil to prevent photo-degradation of the iodine-starch complex. Absorbance (A) was then read using spectrophotometer (Spec $\mathrm{UNICO}^{\circledR} 1100 \mathrm{RS}$, United products and Instruments Inc.) at $620 \mathrm{~nm}$ wavelength. A blank was prepared by following the same procedure, except that no starch sample was added in the volumetric flasks, and used to standardize the spectrophotometer at $620 \mathrm{~nm}$. The amylose content was calculated as:

Amylose content $(\%)=3.06 * \mathrm{~A} * 20$

Amylopectin $(\%)=100 \%$ - Amylose content $(\%)$

Where $\mathrm{A}$ is the absorbance reading at $620 \mathrm{~nm}, 3.06$ is the predetermined gradient of standard amylose calibration curve, and 20 is the dilution factor.

\subsection{Functional Properties of Starch}

\subsubsection{Least Gelation Concentration}

The method of Onwuka (2005) with modification was adopted in the determination of gelation capacity; Starch dispersion $(2-18 \%)$ were prepared in test tubes with distilled water $(5 \mathrm{ml})$. The starch suspensions were thoroughly mixed for $5 \mathrm{~min}$ and heated for $30 \mathrm{~min}$ at $80^{\circ} \mathrm{C}$ in a water bath, followed by rapid cooling under running cold tap $\left(25^{\circ} \mathrm{C}\right)$ water for $2 \mathrm{~h}$.

Least gelation concentration was determined as lowest concentration when the sample from the inverted test tube did not fall down.

\subsubsection{Emulsion Capacity}

Two grams of the native starch was dispersed in 25 millilitres of distilled water using a vortex mixer for $30 \mathrm{~s}$. After complete dispersion, $25 \mathrm{ml}$ of vegetable oil (ground nut oil) was added gradually and the mixing continued for another $30 \mathrm{~s}$. The suspension was centrifuged at $1600 \mathrm{rpm}$ for $5 \mathrm{~min}$. The volume of oil separated from the sample was read directly from the tube. Emulsion capacity was evaluated as the amount of oil emulsified and held per gram of sample (Ihegwuagu et al, 2009). 


\subsubsection{Determination of Water Absorption Capacity (WAC)}

The method of Abbey \& Ibeh (1998) was adopted for determination of water absorption capacity. Starch sample $(1 \mathrm{~g})$ of native and each of the hydroxypropylated water yam starch treatments were weighed separately and distilled water was mixed with it to make up to 10 millilitres of dispersion. It was then centrifuged at $3500 \mathrm{rpm}$ for $15 \mathrm{~min}$. The supernatant was discarded and the tube with its contents reweighed as gram water absorbed per gram of sample. The gain in mass was the water absorption capacity of the flour sample.

\subsubsection{Oil Absorption Capacity (OAC)}

Two grams of sample was mixed with 20 millilitres of oil in a blender at high speed for $30 \mathrm{~s}$. Samples were next allowed to stand at $30^{\circ} \mathrm{C}$ for $30 \mathrm{~min}$ and thereafter centrifuged at $1000 \mathrm{rpm}$ for $30 \mathrm{~min}$. The volume of supernatant in the graduated cylinder was noted. Density of water was taken to be $1 \mathrm{~g} / \mathrm{ml}$ and that of oil determined to be $0.93 \mathrm{~g} / \mathrm{ml}$. The means of triplicate determinations were noted (Abbey \& Ibeh, 1998).

\subsubsection{Effect of Varying Temperatures on Swelling Power and Solubility}

The method of Collado \& Corke (1997) was used in this study with slight modification.Sample (0.5g) was mixed with $15 \mathrm{~mL}$ distilled water in centrifugal tubes. The suspension was heated at $50^{\circ} \mathrm{C}, 60^{\circ} \mathrm{C}, 70^{\circ} \mathrm{C}$ and $80^{\circ} \mathrm{C}$ and $90 \mathrm{C}^{\circ}$ for 30 minutes. The gelatinized sample was cooled to room temperature and centrifuged (HIMAC CR 21GII, Hitachi Koki co. ltd., Japan) at 3500 rpm for 15 minutes. The supernatant was placed in a Petri dish and dried at $100^{\circ} \mathrm{C}$ to constant weight. Solubility was expressed as the weight of dried solid based on weight of dry sample. The swelling power was represented as the ratio in weight of the wet sediment to the weight of initial dry sample. The measurement was in triplicate.

\subsubsection{Starch Gel Clarity}

Starch gel clarity was determined by the method of Bello-Pe'rez et al. (1999) by measuring transmittance of a $1 \%$ $(\mathrm{w} / \mathrm{w})$ starch paste at $650 \mathrm{~nm}$, using a spectrophotometer (Spec UNICO ${ }^{\circledR} 1100 \mathrm{RS}$, United products and Instruments Inc.). Starch suspension in tubes was placed in a water bath at $100^{\circ} \mathrm{C}$ for 30 minutes, vortexed every 5 minutes and left to cool to room temperature. Percentage transmittance $(\% \mathrm{~T})$ was determined in these suspensions.

\subsubsection{Pasting Properties of the Starches}

Pasting properties including pasting temperature, peak viscosity, peak time, trough viscosity, breakdown viscosity, final viscosity and setback viscosity were determined. A mass of sample was weighed into a canister, and a corrected amount of distilled water added. A paddle was placed inside the canister and then centrally into the paddle coupling of the Rapid Visco Analyzer (RVA-super 4, Newport Scientific ${ }^{\circledR}$ Pty Ltd., Warriewood, NSW 2102, Australia) and a RVA Standard Profile procedure employed. The procedure is a 13 minute cycle with temperature regime as follows: An idle temperature of $50^{\circ} \mathrm{C}$ for 1 minute, heating from $50^{\circ} \mathrm{C}$ to $95^{\circ} \mathrm{C}$ in 3 minutes $45 \mathrm{~s}$, holding at $95^{\circ} \mathrm{C}$ for 2 minutes $30 \mathrm{~s}$, cooling to $50^{\circ} \mathrm{C}$ for 3 minutes $45 \mathrm{~s}$, and holding at $50^{\circ} \mathrm{C}$ for 2 minutes. The pasting parameters were calculated using the Thermocline ${ }^{\circledast}$ for Windows ${ }^{\circledR}$ RVA software. In order to further characterize the pasting behaviours, the viscosity breakdown ratio (BDR) was defined as the ratio of trough to peak viscosity, and used to classify the cultivars as highly $(<0.5)$, moderately $(0.5-0.8)$ or slightly $(0.8-1.0)$ shear-thinning, or shear-thickening $(\geq 1.0)$. Analysis was carried out in duplicate.

\subsubsection{Freeze Thaw Stability}

The freeze thaw stability of the starch samples were conducted according to the method described by (Kaur et al., 2004). Aqueous suspension of starch $(5 \% \mathrm{w} / \mathrm{w})$ was heated at $95^{\circ} \mathrm{C}$ under constant agitation for $1 \mathrm{~h}$. The paste was weighed $(20 \mathrm{~g})$ into previously weighed centrifuge tubes and capped tightly. It was centrifuged $(1,000 \mathrm{rpm}$, $10 \mathrm{~min}$ ) to remove free water. The supernatant was decanted and tubes containing starch paste were subjected to eight freeze thaw cycles followed by centrifugation $(4,000 \mathrm{rpm}, 30 \mathrm{~min})$. Alternate freezing and thawing was performed by freezing for $24 \mathrm{~h}$ at $-18^{\circ} \mathrm{C}$ and thawing for $4 \mathrm{~h}$ at $30^{\circ} \mathrm{C}$. The percent water separated after each freeze thaw cycles was measured in terms of syneresis.

$$
\text { Syneresis } \%=\frac{\mathrm{W}_{\mathrm{H}_{2} \mathrm{O}} \mathrm{X} 100}{\mathrm{Ws}}
$$

\subsubsection{FT-IR Spectroscopy}

The IR spectra of starches were run as KBr pellets on FTIR System (Spectrum Two PerkinElmer, England) in the frequency range $350-40000 \mathrm{~cm}^{-1}$ or more according to method of Gbenga et al.,(2014) with slight modifications. Two milligrams of the samples were grounded and mixed uniformly with pure KBr powder. This mixture was 
next placed in an evacuable $\mathrm{KBr}$ die in a $13 \mathrm{~mm}$ clear disk and then pressed in a hydraulic press to form a $\mathrm{KBr}$ pellet using the same amount of pressure $(10,000-15,000 \mathrm{lbs})$ for all samples to avoid polymorphic changes. The pelletized sample was placed in a cell holder (Universal Demountable Cell) and then inserted into the FTIR equipment and scanned at a range of $350-4000 \mathrm{~nm}$ or more. The spectrum and suspected compound was seen displayed and recorded on the computer screen.

\subsection{Statistical Analysis}

All analysis were carried out in triplicate except otherwise stated. One-way analysis of variance was performed to determine significant differences $(\mathrm{P}<0.05)$ between means and Duncan's multiple range test was used to separate means using SPSS version 20.

\section{Results and Discussion}

\subsection{Extraction and Yield of Native Water Yam Starch}

The yield obtained from the water yam extraction was $84.2 \%$ (dry weight basis). The yield is greater than values obtained by Verwimp et al,. (2004) for rye starch (42.2\%) and Chavan et al. (2010) for horse gram starch (22 to $31 \%$ ) but less than values obtained by Nadiha et al. (2010) for sago, potato and corn starches, which were $93.6 \%$, 93.4\% and 96.5\% respectively. Starch yields of 49.3 and 59.3\% for pigeon pea and mung bean starches, respectively had been reported by Mwetta, (2009). Similarly, Barimalaa et al. (2005) reported starch yields of 47.9, 45.52 and $42.75 \mathrm{~g} / 100 \mathrm{~g}$ seed from four different varieties of bambara groundnut. Banigo \& Mepba (2008) reported starch yields of 45.9-47.1 and 54.6\% for African yam bean and cowpea starches respectively. The major component of the tubers is starch, which can amount up to $85 \%$ of total dry weight of the tuber such as in Dioscorea alata (Huang et al., 2006).Variation in the starch content is related to the maturity stage, variety, different climatic and agronomic conditions (Rahman et al., 1999).The high yield most probably is due to the granular size which allows for easy extraction of the starch granule.

\subsection{Molar Substitution of Hydroxypropylated Water Yam Starch}

The molar substitution (MS) of the hydroxypropyl group into granular starches was used to measure the reaction efficiencies of hydroxypropylation and cross-linking. The MS of the starch with 4-12\% propylene oxide are as shown in table 1 . The hydroxypropyl groups and MS reflecting the effect of hydroxypropylation were in the range $0.087-1.823 \%$ and $0.002-0.05$ respectively. It was observed that there were progressive increases in MS as the volume of propylene oxide added to the reaction medium rose; the highest MS attained being 0.05. Corresponding increases were also noted in molar substitution (MS) with the addition of propylene oxide during the hydroxypropylation of white yam (Lawal, 2008). This observation is consistent with increases in the MS of hydroxypropyl finger millet starch as the volume of propylene oxide added to the reaction mixture increased (Lawal, 2008). A similar observation was also reached with the hydroxypropylation of canna and maize starches (Chuenkamol et al., 2007). Higher concentration of propylene oxide resulted in greater rate of collision between the starch alkoxide and the reagent in the proximity of starch granule (Lawal, 2009) causing higher degree of substitution.The reaction efficiency of hydroxypropylation depends on the diffusion or penetration of the alkaline catalyst and the etherifying agent into the starch granules and the probability of reactivity between the starch alcoholate nucleophile and the propylene oxide molecule (Vorwerg et al, 2004). Higher concentration of propylene oxide enhanced the probability of its reactivity with the starch alcoholate nucleophile. This observation is consistent with previous reports on hydroxypropylation of wheat starch (Choi \& Kerr, 2003).Also in the succinylation of acha starch, the results indicated that \% succinylation increased with increase in concentration of succinic anhydride (Arueya \& Oyewale, 2014). The substitution reaction by etherification initially requires starch activation by an alkaline agent to facilitate the $\mathrm{O}-\mathrm{H}$ nucleophillic bond, in addition to forming the starch $\mathrm{O}$. This reactive starch type (O.) reacts with a substituting molecule, the propylene oxide, resulting in a bimolecular substitution and hydroxypropyl starch. Recommendations regarding the permitted substitution for hydroxypropylated starches, limit the value of the degree of substitution to 0.2 for use in food formulations (Dias et al., 1997).

Studies by Pal et al. (2000) with corn and amaranto hydroxypropylated starches indicated that recommendations do not consider the specificity of each starch. The highest MS reported here is 0.17 and that is within the limit allowed for the use of hydroxypropylated starch in food applications (Dias et al., 1997), which translates to an upper limit of $\mathrm{MS}=0.2$ i.e. $7.0 \mathrm{~g} / 100 \mathrm{~g}$ i.e. $\mathrm{MS}=0.2$ Native starch has distinct morphological, functional and physical chemistry characteristics, which would require a molar substitution limit for each type of starch. Significant difference among these values indicated the effects of the volume of propylene oxide used for the substitution reaction. The hydroxyl groups of starch can be reactive and substituted by a range of functional groups for modifications (Mweta, 2009). Substitution degree is an important parameter in the evaluation of the 
etherification process, identifying the number of substituting group moles per glucose unit, where this definition only applies to polymeric substitution (Mweta, 2009).Yam starches from several species have been subjected to hydroxypropylation (Lawal et al., 2008b; Odeku \& Picker-Freyer, 2009) with a concomitant enhancement in their hydrophilic properties.

Table 1. Conditions of synthesis and the resulting molar substitution of hydroxypropylated water yam starch

\begin{tabular}{llllllll}
\hline Sample & Starch $(\mathrm{g})$ & $\mathrm{Na} 2 \mathrm{SO} 4(\mathrm{~g})$ & Propylene oxide $(\mathrm{ml})$ & Temperature $\left({ }^{\circ} \mathrm{C}\right)$ & $\mathrm{pH}$ & Time $(\mathrm{hr})$ & $\mathrm{MS}$ \\
\hline $4 \%$ HPS & 100 & 20 & 4 & 40 & 10.5 & 24 & 0.0024 \\
$6 \%$ HPS & 100 & 20 & 6 & 40 & 10.5 & 24 & 0.021 \\
$8 \%$ HPS & 100 & 20 & 8 & 40 & 10.5 & 24 & 0.024 \\
$10 \%$ HPS & 100 & 20 & 10 & 40 & 10.5 & 24 & 0.032 \\
$12 \%$ HPS & 100 & 20 & 12 & 40 & 10.5 & 24 & 0.05 \\
\hline
\end{tabular}

\subsection{Physical Properties of Water Yam and Starch Extract (Native and Hydroxypropylated)}

\subsubsection{Dimensions of the Water Yam Tubers}

The tubers were more uniform (Figure 1) in geometry (length, width), weight and shapes. The length of the water yam tubers ranged from $197.35 \mathrm{~mm}$ to $227.06 \mathrm{~mm}$. Techi et al, (2012) reported length of $44.07 \mathrm{~cm}$ for some cultivars of water yam. The width of the water yam ranged from $148.03 \mathrm{~mm}$ to $160.8 \mathrm{~mm}$. The Shapes were regular gourd and consistent. Small variances were though observed in the dimensions.

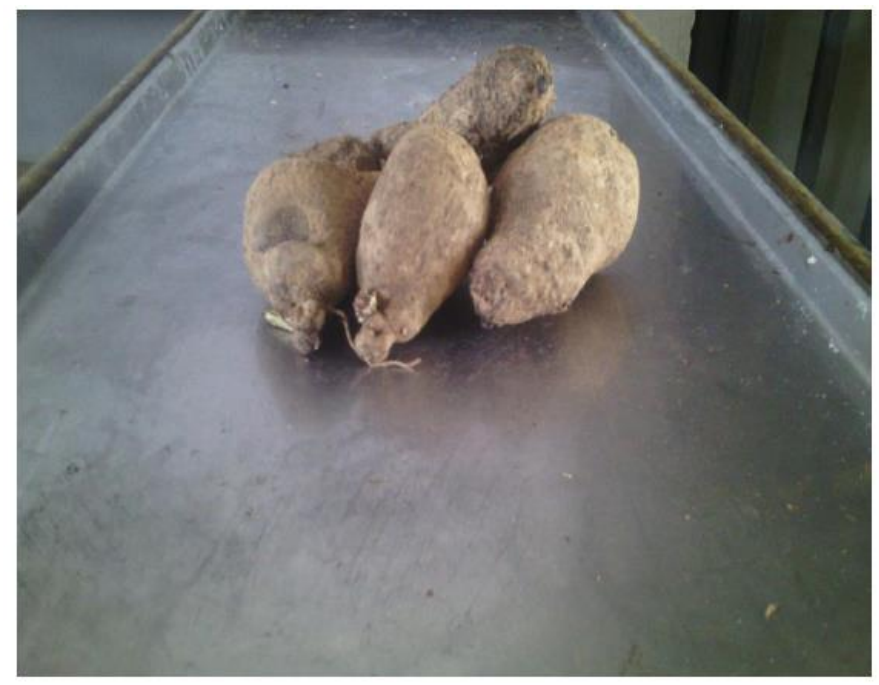

Figure 1. Water yam tubers

\subsubsection{Granule Morphology of the Native and Hydroxypropylated Water Yam Starch}

The granule morphology and size distribution of native and hydroxypropylated water yam starches reflected a size distribution pattern (Table 2).Native water yam starch granules showed various shapes: triangular, round, oblong, oval and oval-triangular with the last three being predominant. Few round shapes were observed and similar to other studies [Tetchi et al., (2012), Otegbayo et al. (2011), Rugchati \&Thanacharoenchanaphas (2010)]

The Native water yam starch gave size distribution range of $8.06-72.5 \mu \mathrm{m}$ with mean $(33.882 \mu \mathrm{m})$, median $(34.1 \mu \mathrm{m})$, mode $(30.24 \mu \mathrm{m})$ dimensions. Naknaen $(2014)$ also reported that the shape of jackfruit native starch appeared irregular, round to bell or semi-oval with an average size of $7.66 \mu \mathrm{m}$. For the $4 \%$ HPS, the interval size distribution is $8.58 \mu \mathrm{m}-62.99 \mu \mathrm{m}$ with mean, median and mode dimension to be $28.36 \mu \mathrm{m}, 29.31 \mu \mathrm{m}$, and $29.71 \mu \mathrm{m}$ respectively. The size distribution range of $4 \% \mathrm{HPS}$ is similar to that of native starch with the upper range lower than that of native starch. The highest size $(62.99 \mu \mathrm{m})$ at this concentration is evidently reduced when compared to the native starch. Similar trend was observed with the values of mean, median, and mode indicating reduction in sizes with a subsequent reduction in the percentage of small and large granules. The hydroxypropylated granules at 4\%HPS still maintained their granular form without fragmentation. In contrast, Schmitz et al., (2009) reported that hydroxypropylated cassava starch exhibited natural granule alteration from the native form. Recently, Perera et al. (1997) using X-ray diffraction showed that hydroxypropylation caused 
profound changes in physical arrangement of starch chains within the amorphous and crystalline domains of starch granules, Changes in the morphology of starch granules was reported in the alkaline treatment of sago, potato and corn starches(Nadiha, 2010). Based on the morphology and granule size, yam starch granule is closely related to potato starch. In terms of size distribution, yam starch has distribution pattern different from tapioca and potato associated with symmetrical distribution (Hossen, et al., 2011).

Variations in amylose and amylopectin structures and their relative amounts in a granule play an important role in controlling starch granule size and shape. Activity of the enzyme granule bound starch synthase (GBSS) during growth may also affect starch granule morphology (Blennow et al., 2002). The membranes and the physical characteristics of the plastids have been linked to a particular morphology of starch granules during development (Jane et al., 1994; Lindebooma et al., 2004).

Among samples of $6 \%$ HPS, the percentage of small and large granules increased by $1.55 \%$ and $8.64 \%$ respectively. There is no fragmentation or change in shape of the granules observed. This is in agreement with findings on hydroxypropylation of jackfruit (Naknaen, 2014) where the modified granules were still intact, free of fragmentation. However, the presence of traces of degradation was observed on some starch granules, particularly at higher level of propylene oxide $\left(\mathrm{HP}_{40}-\mathrm{HP}_{50}\right.$ ). Also oxidation of native acha starch did not affect the shape, appearance and structural arrangement of the starch granules (Isah et al., 2015) but contrast with Singh et al,. (2006) where the presence of small protruberances and fragmentation on the surface of potato starch granules were observed. Physico-chemical properties, such as transparency of the starch paste, enzymatic digestibility, amylose content and swelling power have been significantly correlated with the average granule size of the starches separated from different potato cultivars (Kaur et al., 2007a, b). It is obvious from a cursory look at Table 2 that the level of modification influenced the size and size distribution of the water yam starch granules. Paradoxically, while Chuenkamol et al., (2007) reported surface alteration of canna starch granules on hydroxypropylation, it was not the case with potato starch as its morphology remained intact (Kaur et al., 2004).

Granule diameter is an important parameter in particle-particle interactions, mixing and homogeneity in food product formulation (Riley et al., 2008).

Generally, small and medium sized starch granules have been reported to have varied utilization in the food industry (Omojola et al, 2010) which makes both the native and modified starch desirable both in the food and other industrial applications. Granule size and size distribution of starch are unique properties of starch that have an influence on the functionality of the starches. Granule shape of starches does not influence their functional properties but can be used to identify the source of the starch. Granule size affects starch functionality being a contributing factor to its extractability (ease of starch extraction and sedimentation), pasting properties swelling power, gelatinization temperature, and viscosity (Sanguanpong et al, 2004). Recent works have proved the importance of understanding the starch granule morphology, such as the influence of the process in starch granule structure. Perera \& Hoover (1999) observed the structure of defatted potato starch granules treated with humid heat. Marcon (2004) used microstructure examination to reveal the effect of the cassava starch sour improved fermentation on several origins of starch granule structure. Kaur et al. (2004) developed studies on hydroxypropylated potato starch and the influence of this process on native potato starch microstructure.

Table 2. Granule morphology and size distribution of native and hydroxypropylated water yam starch

\begin{tabular}{|c|c|c|c|c|c|c|c|}
\hline Sample & Predominant shapes & $\begin{array}{l}\text { Interval size } \\
\text { Distribution }(\mu \mathrm{m})\end{array}$ & $\begin{array}{l}\text { Mean } \\
(\mu \mathrm{m})\end{array}$ & $\begin{array}{l}\text { Median } \\
(\mu \mathrm{m})\end{array}$ & $\begin{array}{l}\text { Mode } \\
(\mu \mathrm{m})\end{array}$ & $\begin{array}{l}\text { Small } \\
\text { Granule }(\%)\end{array}$ & $\begin{array}{l}\text { Large } \\
\text { granule }(\%)\end{array}$ \\
\hline Native & $\begin{array}{l}\text { Round, elongated oval, } \\
\text { ellipsoid, triangle }\end{array}$ & $8.06-72.5$ & $33.88 \pm 1.3$ & 34.10 & 30.24 & 25.02 & 42.81 \\
\hline $4 \%$ HPS & $\begin{array}{l}\text { Round, elongated oval, } \\
\text { ellipsoid, triangle }\end{array}$ & $8.58-62.99$ & $28.36 \pm 1.2$ & 29.31 & 29.71 & 20.38 & 34.92 \\
\hline $6 \%$ HPS & $\begin{array}{l}\text { Round, elongated oval, } \\
\text { ellipsoid, triangle }\end{array}$ & $6.46-73.64$ & $32.63 \pm 1.3$ & 30.99 & 27.39 & 21.55 & 43.56 \\
\hline $8 \%$ HPS & $\begin{array}{l}\text { Round, elongated oval, } \\
\text { ellipsoid, triangle }\end{array}$ & $8.58-72.5$ & $31.16 \pm 1.2$ & 30.24 & 29.31 & 21.32 & 38.90 \\
\hline $10 \% \mathrm{HPS}$ & $\begin{array}{l}\text { Round, elongated oval, } \\
\text { ellipsoid, triangle }\end{array}$ & $6.46-82.28$ & $30.69 \pm 1.5$ & 28.23 & 48.53 & 18.04 & 38.90 \\
\hline $12 \% \mathrm{HPS}$ & $\begin{array}{l}\text { Round, elongated oval, } \\
\text { ellipsoid, triangle }\end{array}$ & $10.75-58$ & $33.43 \pm 1.1$ & 33.83 & 29.71 & 24.26 & 43.53 \\
\hline
\end{tabular}

Means in columns are significantly different at $5 \%$ level $(\mathrm{P}<0.05)$.Small granules $(1-10 \mu \mathrm{m})$, Large granules $(>25 \mu \mathrm{m})$ 


\subsubsection{Loose and Packed Bulk Densities of Native and Hydroxypropylated Water Yam Starch}

Table 3 shows the loose and tapped bulk densities, Hausner ratio, Carr index, compressibility and flowability of the starches. Loose bulk density ranges from $0.5-0.6005$ in the order of $4 \%$ to $12 \%$ for the hydroxypropylated starch while that of native starch is 0.4988 .Packed bulk density showed similar trend. This followed the pattern of decrease in amylose content and it was also observed that hydroxypropylation has effect on the particle size of the granules.

Hydroxypropylation increased both the loose and packed bulk densities and this was reflected in the particle sizes. Thus, $12 \%$ HPS had the highest loose and packed densities. Starch with the highest granule size gives an indication of the greater ease of dispersability and reduction of paste thickness (Udensi \& Eke, 2000). Low bulk density of starch is a good physical attribute when determining transportation and storability since the products can be easily carried and distributed to locations where they are required (Agunbiade \& Sanni, 2003). Low bulk density is advantageous for the infant food as both calorie and nutrient intake are enhanced per feed (Onimawo \& Egbekun, 1998). High bulk density is a good physical attribute when determining mixing quality of particulate matter (Lewis, 1990). The bulk density of the cereal starch was less than the potato starch $(0.98 \mathrm{~g} / \mathrm{mL}$ ) (Singh et al., 2009). The modified water yam starches had higher bulk densities than the native starch. Bulk density of foods increases with increase in starch content (Bhattacharya \& Prakash, 1994). High bulk density of protein material is important in relation to its packaging (Okezie \& Bello, 1988). The results of the bulk density of the starch samples also showed that the native starch from the water yam will be good for developing foods that requires more protein while the hydroxypropylated starches will be good for energy foods.

Bulk density is an important parameter for determining industrial requirements for packaging, material handling and utilization in wet processes in the food industry (Muazu et al., 2011) Starch flours with high bulk densities such as 4\% HPS to 12\% HPS could be used as thickeners (Ocloo et al., 2010). The parameters of Carr's index and Hausner ratio predict the flow and compressibility of powders (Muazu et al., 2011). In literature, Hausner ratio above 1.2 and Carr's index above $23 \%$ do not indicate good flow or good compressibility (Iheagwara, 2013).

Carr index and Hausner ratio for the native and hydroxypropylated water yam starch was in order of: native water yam starch $(24.0,1.2531)<8 \%$ HPS, $(31.0,1.2333)<6 \% \operatorname{HPS}(33.0,1.3571),<4 \% \operatorname{HPS}(33.3,1.333)<$ $12 \%$ HPS $(35.2,1.4167)<10 \% \operatorname{HPS}(35.8,1.4583)$.

The Carr index provides an indirect measure of material fluidity, and the higher its value, the more cohesive the substance (Riley et al., 2008). The 4-12\% HPS samples were indicated less suitable values in flowability but good for compressibility. Ostensibly, hydroxypropylation improved compressibility but not flowability of water yam starch. This differs from the results reported by Olorunsola et al., (2011) for native and acid hydrolysed sweet potato starch. The lower the Carr index of a material, the lower the porosity, the better the flowability, but the poorer the compressibility. Therefore, the improvement or otherwise of compressibility and flowability of hydroxypropylated water yam starches depend on the increase in molar substitution.

Table 3. Densities and flow characteristics of native and hydroxypropylated water yam starch

\begin{tabular}{lllllll}
\hline Sample & Loose bulk density & Packed bulk density & Hausner ratio & Carr index $(\%)$ & Compressibility & Flowability \\
\hline Native & $0.4988 \pm 0.0$ & $0.6187 \pm 0.1$ & $1.2531 \pm 0.1$ & 24.0 & Fair & Poor \\
$4 \%$ HPS & $0.5 \pm 0.0$ & $0.6667 \pm 0.1$ & $1.3333 \pm 0.1$ & 33.3 & Good & Very poor \\
$6 \%$ HPS & $0.5130 \pm 0.0$ & $0.6897 \pm 0.1$ & $1.3571 \pm 0.1$ & 33.0 & Good & Very poor \\
$8 \%$ HPS & $0.5266 \pm 0.0$ & $0.6867 \pm 0.1$ & $1.2333 \pm 0.1$ & 31.2 & Fair & Very poor \\
$10 \%$ HPS & $0.5826 \pm 0.0$ & $0.7692 \pm 0.1$ & $1.4583 \pm 0.1$ & 35.8 & Excellent & Very poor \\
$12 \%$ HPS & $0.6005 \pm 0.0$ & $0.8 \pm 0.0$ & $1.4167 \pm 0.1$ & 35.2 & Excellent & Very poor \\
\hline
\end{tabular}

Means in columns are significantly different at $5 \%$ level $(\mathrm{P}<0.05)$. Carr index of 5-10,12-16,18-21,23-28 represent excellent, good, fair, and poor flowability respectively. Flowability is conversely related to compressibility.

\subsubsection{Colour Evaluation of Native and Hydroxypropylated Water Yam Starch}

The colour of starch due to the presence of polyphenolic compounds, ascorbic acid and carotene has impact on its quality. Table 4 shows the result from the colour evaluation of native and hydroxypropylated water yam starches. $\mathrm{L}^{*}$ (lightness) ranged from 83.0 for the native starch to 93.2 for the $12 \% \mathrm{HPS}$, a*(Red/green) ranged from 0.6 to 0.0 for native and 12\%HPS respectively and $b^{*}$ (yellow/blue) ranged from 1.5 for native water yam starch to 3.0 for $12 \%$ HPS.L $*$ followed the order of native $<4 \%$ HPS $<6 \%$ HPS $<8 \%$ HPS $<10 \%$ HPS $<12 \%$ HPS. 
Evidently, the 12\%HPS sample had the highest value of lightness (93.2) followed by $10 \%$ HPS (91.9), $8 \%$ HPS (91.6), 6\%HPS (90.8), 4\%HPS (88.5).The result showed significant increase in lightness, $\mathrm{L}^{*}$ and $\mathrm{b}^{*}$ for all the hydroxypropylated water yam starches but $\mathrm{a}^{*}$ magnitude reduced significantly compared to the native starch. These changes can be attributed to some level of removal of extraneous matter like proteins, fat, fibre, latex, salts, sugars, pigments during hydroxypropylation. Starch isolate obtained by Shimelis et al. (2006) from improved bean (Phaseolus vulgaris L.) was deemed pure and of acceptable colour extraction following treatment with $\mathrm{NaOH}$ and $\mathrm{NaNO}_{3}$ solution, during which compounds such as polyphenols, ascorbic acid and carotene were eliminated.The residual polyphenols, ascorbic acid and carotene carried over to the final starch product may have been responsible for the relatively lower lightness values (81.26-88.42) (Shimelis et al.,2006). The observed colour values suggest that $12 \%$ HPS is more yellowish in colour than other hydroxypropylated water yam starches. The presence of inherent pigments in the starch if carried over to the final product reduces the quality hence acceptability of starch product (Galvez \& Resurreccion, 1992).

Table 4. Surface colour of native and hydroxypropylated water yam starch

\begin{tabular}{llllllllll}
\hline Sample & $\mathrm{L}^{*}$ & $\mathrm{a}^{*}$ & $\mathrm{~b}^{*}$ & $\mathrm{H}^{*}$ & $\Delta \mathrm{C}$ & $\Delta \mathrm{E}$ & $\mathrm{W}(\%)$ & $\mathrm{C}^{*}$ & $\mathrm{E}^{*}$ \\
\hline Native & $83.0 \pm 0.0$ & $0.6 \pm 0.0$ & $1.5 \pm 0.0$ & $66.8 \pm 0.2$ & $9.2 \pm 0.0$ & $14.19 \pm 0.0$ & $44.2 \pm 0.0$ & $1.6 \pm 0.0$ & $10.87 \pm 0.0$ \\
$4 \%$ HPS & $88.5 \pm 0.1$ & $0.4 \pm 0.0$ & $2.9 \pm 0.0$ & $82.6 \pm 0.0$ & $8.0 \pm 0.0$ & $9.6 \pm 0.0$ & $53.29 \pm 0.1$ & $2.9 \pm 0.0$ & $6.02 \pm 0.1$ \\
$6 \%$ HPS & $90.8 \pm 0.0$ & $0.2 \pm 0.0$ & $3.9 \pm 0.0$ & $86.9 \pm 0.0$ & $7.2 \pm 0.0$ & $7.8 \pm 0.0$ & $57.86 \pm 0.0$ & $3.9 \pm 0.0$ & $4.91 \pm 0.0$ \\
$8 \%$ HPS & $91.6 \pm 0.0$ & $0.07 \pm 0.0$ & $2 . .5 \pm 0.0$ & $88.3 \pm 0.1$ & $8.1 \pm 0.0$ & $8.4 \pm 0.0$ & $59.84 \pm 0.1$ & $2.5 \pm 0.0$ & $3.3 \pm 0.0$ \\
$10 \%$ HPS & $91.9 \pm 0.0$ & $0.03 \pm 0.0$ & $3.3 \pm 0.2$ & $89.5 \pm 0.0$ & $7.5 \pm 0.1$ & $7.7 \pm 0.1$ & $60.6 \pm 0.1$ & $3.3 \pm 0.2$ & $3.7 \pm 0.2$ \\
$12 \%$ HPS & $93.2 \pm 0.0$ & $0.01 \pm 0.0$ & $3.0 \pm 0.0$ & $89.8 \pm 0.0$ & $7.7 \pm 0.0$ & $7.7 \pm 0.0$ & $63.6 \pm 0.1$ & $3.0 \pm 0.0$ & $3.02 \pm 0.0$ \\
\hline
\end{tabular}

Means of columns are significantly different at $5 \%$ level $(\mathrm{P}<0.05)$

\subsection{Chemical Properties of Native and Hydroxypropylated Water Yam Starch}

\subsubsection{Proximate Composition}

Table 5 shows the proximate composition of the native and hydroxypropylated water yam starches. The range of the moisture content of the native water yam starch was 10.47 while those of the hydroxypropylated starches ranged from $12.01 \%$ to $14.01 \%$. The moisture content for the hydroxypropylated water yam starches are higher than that of its native counterpart but it reduces as the volume of propylene oxide increases. This is at variance with the moisture content of saba banana starch which was $11.4 \%$, whereas the moisture content of hydroxypropylated banana starches ranged between 7.3 - 10.8 \%.( Jau-Shya, Lee et al, 2011).High moisture content promotes microbial deterioration and also enhances discolouration of starches. This observation is similar to that of annealed African yam bean starch, bambara groundnut starch and mucuna bean starch which was reported to have higher moisture than those of their native starches (Adebowale et al., 2009; Adebowale \& Lawal, 2002; Adebowale \& Lawal, 2003).The lower moisture content of the hydroxypropylated starches at high concentration of propylene oxide indicates decreased susceptibility to microbial attack, less ability to interact with foods that are moisture sensitive and high ability to absorb water ,although the moisture content of modified starches were within official limit $4 \%$ to $12 \%$ (Olayemi, 2008). High moisture may lead to activation of enzymes and proliferation of micro-organisms.

As shown in the result, the crude protein decreased as the volume of propylene oxide increased i.e. increase in degree of substitution decreased the crude protein content Protein content of yam starches varied greatly among different reports, with most of the reports showing a value of $<0.2 \%$. The discrepancy between different studies is most likely attributable to isolation methods and crop genetics. Lower protein content is a reflection of a more efficient extraction method for purifying the starch (Baldwin, 2001).Protein content of the native water yam starch is also low compared to other native leguminous starches, an indication of the absence of endosperm proteins and non-starch lipids. Notably, the nitrogen content of isolated starch represents the endosperm storage proteins, lysophospholipids and proteins located inside starch granules (Chavan et al., 2010). This could also be a function of the cultivar (Bartova et al., 2006). The amount of protein is usually considered as an index of purity of legume and cereal starches.It has been reported that yam starches have higher CP than sweet potato starch (Ali et al., 2012) and cassava starch (Nuwamanya et al. 2010). Interestingly, Adebowale et al. (2009) reported reduced crude protein for annealed African yam bean starch. Most proteins precipitate out of solutions when adjusted to their iso-electric point, that is when $\mathrm{pH}$ equals pKa (Belitz et al., 2009) and acid-thinned hybrid maize starch has also been found to have lower crude protein than its native starch (Lawal et al., 2005). Hydroxypropylated starches had lower protein than native starch probably as a result of the high oxidative and denaturing property it possesses on proteins. The denatured protein bodies eventually precipitate out, and are 
decanted, thus leading to a reduction of proteins in the starch.

Crude fat of the starches ranged from $0.14 \%$ (12\%HPS) to $1.06 \%$ (native starch) following the order: Native starch > 4\%HPS (0.73) > 6\%HPS (0.61) >8\%HPS (0.50) > 10\%HPS $(0.32)>12 \%$ HPS (0.14).Lipids-starch interaction may influence functional, thermal and retrogradation properties of starches (Singh \& Kaur, 2009). Similar values have been reported for Chinese yam starches (Odeku \& Picker-Freyer, 2007); and D. cayenensis-rotundata starch (Zuluaga et al., 2007).The modification (hydroxypropylation) significantly reduced the crude fat of the native starch.

Ash content of the native starch was 1.35 which is higher compared to its hydroxypropylated water yam starches. This is at variance with the findings of Schmitz et al., (2006) that hydroxypropylated starch ash content of cassava was superior to the native starch. However, the ash content is still a bit similar to the ash content $(0.30 \pm$ $0.011 \%$ ) of sweetsop and soursop starches (Nwokocha \& Williams, 2009), lower than that of treculia africana starch (Nwokocha \& Ogunmola, 2005) and cocoyam starch and within the same value as that of cassava starch (Nwokocha et al., 2009). Hydroxypropylated ash content ranged from 0.22 (12\%HPS) to 0.34 (10\%HPS) to 0.45 (8\%HPS), 0.66 (6\%HPS) to 0.89 (4\%HPS),a decrease in ash content was observed as the molar substitution increased. Ash content for native water yam starch $(1.35 \%)$ was superior to the modified starches. The ash content which measures the bulk of the residue left after burning, it is also often indicative of the metallic content, all starches contain mineral ions. The ash content is the composite of all inorganic minerals in the starches

Crude fibre was not detected in the native and hydroxypropylated starches, this is similar to other observations (Odeku \& Picker-freyer, 2007, Adebowale et al., 2002; Olayinka et al., 2011). However, Rugchati \& Thanacharoenchanaphas, 2010 reported low crude fibre for water yam starch.

Nitrogen free extract, NFE represents all the carbohydrate components of the starch, and it ranges from 84.957 to $87.622 \%$.The highest carbohydrate content in this study was $87.622 \%$ (12\%HPS) with no significance difference $(P>.05)$ within the varieties.

Table 5. Chemical composition of native and hydroxypropylated water yam starc

\begin{tabular}{llllllll}
\hline Sample & Moisture \% & Ash content $\%$ & Crude fat & Crude protein & NFE $\%$ & Amylose \% & Amylopectin \% \\
\hline Native & $10.47 \pm 0.0$ & $1.35 \pm 0.0$ & $1.06 \pm 0.07$ & $0.183 \pm 0.1$ & 86.937 & $44.186 \pm 0.1$ & 55.814 \\
$4 \%$ HPS & $14.01 \pm 0.1$ & $0.89 \pm 0.0$ & $0.73 \pm 0.05$ & $0.093 \pm 0.0$ & 84.957 & $41.942 \pm 0.7$ & 58.058 \\
$6 \%$ HPS & $13.70 \pm 0.2$ & $0.66 \pm 0.0$ & $0.61 \pm 0.04$ & $0.092 \pm 0.0$ & 85.508 & $40.841 \pm 0.3$ & 59.159 \\
$8 \%$ HPS & $13.1 \pm 0.1$ & $0.45 \pm 0.0$ & $0.50 \pm 0.07$ & $0.009 \pm 0.0$ & 86.371 & $40.208 \pm 0.1$ & 59.792 \\
$10 \%$ HPS & $12.39 \pm 0.3$ & $0.34 \pm 0.0$ & $0.32 \pm 0.04$ & $0.009 \pm 0.0$ & 87.321 & $37.475 \pm 0.1$ & 62.525 \\
$12 \%$ HPS & $12.01 \pm 0.0$ & $0.22 \pm 0.0$ & $0.14 \pm 0.04$ & $0.008 \pm 0.0$ & 87.622 & $36.252 \pm 0.0$ & 63.296 \\
\hline
\end{tabular}

Means in columns are significantly different at $5 \%$ level $(\mathrm{P}<0.05)$

\subsubsection{Amylose and Amylopectin Content of Native and Hydroxypropylated Water Yam Starch}

Table 5 above also showed the amylose and amylopectin content of the native and hydroxypropylated water yam starch ,the amylose content ranged from $44.186 \%$ for the native starch,41.942\% 94\%HPS),40.841\% (6\%HPS),40.208\% (8\%HPS), 37.475\% (10\%HPS), $43.166 \%$ (12\%HPS).The amylose content of the hydroxypropylated starches varied significantly $(P<0.05)$ and $12 \%$ HPS was found to have the lowest $(36.112 \%)$ while $4 \%$ HPS had the highest $(41.942 \%)$. The amylose content of the native and the hydroxypropylated water yam starches are significantly different. Amylose content decreased with hydroxypropylation, an observation comparable to those from alkaline treatment of potato, sago and corn starches (Nadiha et al,2010).The reduction of apparent amylose content of hydroxypropylated starches (Table 5) could be attributed to the disruption of the amorphous region containing amylose chains (Karim et al., 2007). In addition, the propylene oxide appears to affect more of the amylose rather than the amylopectin molecules and/or regions of the granules (Lai et al., 2004). Lai et al. (2004) further suggested that the ions in propylene oxide solution diffuse into the amylose-rich amorphous regions of the granules, break intermolecular bonds, and cause the granules to swell to a higher degree with a concomitantly higher exudation of amylose. The amorphous regions in different starches might differ in terms of dimension and molecular arrangement (Wang \& Wang, 2001). Amylose content of yam starch is reported to be between 14-30\% depending on the species (Moorthy, 2002). Oke et al. (2013) reported comparable amylose contents of between $27.47-41.90 \%$ for ten water yam cultivars' starches. In a similar development, Otegbayo et al. (2011) observed amylose content for native water and white yam starches as $28.99-33.11 \%$ and $27.45-32.80 \%$ respectively, along with a validated value (27.44-33.03\%) for 18 white yam 
cultivars' starches. Differences in amylose/amylopectin ratio of starches might also occur because of the activity of the enzymes involved in starch biosynthesis of various starches (Krossmann \& Lloyd, 2000), genetic variations, climatic conditions, cultivation practices and botanical source (Odeku \& Picker-Freyer, 2007). The amylose content of the native starch was $41.942 \%$ which is higher than those reported by Hoover \& Senanayake (1996) for oat (22.2 to 22.5\%), Sandhu \& Singh (2007) for corn (16.9 to 21.3\%), and Chavan et al.,(2010) for Horse Gram (34.00 to 36.30\%) starches. The amylose content of starch determines crystallinity and thus affects solubility (Yuan et al., 2007), factors important in determining the applicability of the starch. Amylose is essentially a linear polymer of 1,4-linked $\alpha$-D-glucopyranose units constituting about $15-20 \%$ of the starch contrasting sharply with amylopectin, a highly branched polymer of 1,4 and 1,6 linked D-glucopyranosyl units (80-85\%.of the starch). It is also a measure of the tackiness of the starch. Amylose content in yam starches also varied considerably according to various reports.(Farhat et al.,2009) have obtained the following values for amylose content in starches of different Dioscorea species $-D$. alata $-25 \%, D$. rotundata and D. cayensis $-23.8 \%$ and $D$. dumetorum $-12.6 \%$. A value of $29.7 \%$ was reported for the amylose content of $D$. abyssinica starch from Ethiopia, while Asaoka \& Blanshad, (1991) obtained $24.1 \%$ for D. ballophylla starch. Only very little variation in the amylose content was observed with age of the crop for D. esculenta, D. alata and D. rotundata starches.

As shown in Table 5, the value of amylose content for native water yam starch is higher than those of hydroxypropylated starches, a fact confirmed by Perera et al. (1997) who observed decreased amylose leaching for hydroxypropylated potato starch. It has been reported that amylose is derivatized to a greater extent than amylopectin (Shi \& BeMiller, 2002; Kavitha \& BeMiller, 1998) and that derivatization increased the amylose leaching. Thus, the reduction in amylose content of hydroxypropylated water yam starches may have been due to some amylose leaching during the hydroxypropylation process, as well as partial hydrolytic effect of the mild heat treatment which may have led to lysis of some glucosidic bonds in the amylose chains found in the amorphous region of the starch granules.

Environmental factors and agronomic practices can greatly affect the amylose content of yam starches (Huang et al., 2006; P'erez et al., 2011; Akinoso \& Abiodun, 2013; Otegbayo et al., 2014). Drought decreased the amylose content of starch from D. dumetorum (Otegbayo et al., 2014). The harvesting year was found to influence the amylose content of starch from D. trifida (P'erez et al., 2011). Harvesting month (from 7 to 11 months since planting) had little effect on the amylose content of starch from D. dumetorum (Akinoso \& Abiodun 2013). In contrast, starch from $D$. alata harvested at the 260th day (about 9 months) after planting had higher amylose content than when harvested earlier (Hung et al., 2006). This discrepancy may be attributed to the differences in the harvesting period, yam genotype, and some environmental conditions. With a 3-month postharvest storage, the amylose content of starch from tubers of D. Alata decreased (Brunnschweiler, et al., 2005). Amylose is a major component of starch and plays an essential role in the properties and uses of starch (Srichuwong \& Jane 2007). Functional properties of starches depend on the amylose content to a large extent (Awokoya et al., 2011). Great variation in the amylose content of diverse genotypes of the same species and between diverse species has been observed. Amylose contents of genotypes from various yam species ranged from 1.4\% (P'erez et al., 2011) to 50\% (Rolland-Sabat'e et al., 2003). Apparent amylose content from 43 genotypes in 5 species ranged from $15.1 \%$ to $27.1 \%$ (Otegbayo et al., 2014). Among the most studied species, D. dumetorum and D. esculenta tend to have lower amounts of amylase $(<20 \%)$ compared to $D$. alata, D. rotundata, D. cayenensis-rotundata, and $D$. cayenensis (>20\%) (Amani et al., 2004; Otegbayo et al., 2014). Amylose content in distal and proximal regions of tubers of $D$. alata is rather similar (Brunnschweiler et al., 2005), indicating an even distribution of amylose through the whole tubers. These environmental and human factors suggest possible manipulation of the amylose content of starch to further artificially diversify the variation.

Hydroxypropylation of water yam starch reduced ash content, protein, fat, amylose and $\mathrm{pH}$. These reductions were probably due to degradations of starch during the chemical modification process. The chemical composition is a simple and convenient way of illustrating the purity of the starch extracts, whereby higher starch and lower contents of other components (protein, fat, ash, and fibre) are highly desirable. The protein, fat, ash and fibre contents of hydroxypropylated Water yam starch were lower than the native starch. The results indicate that pure starch could be obtained from water yam through hydroxypropylation. The result also implied that native water yam starch is less pure compared to the hydroxypropylated water yam starches.Report of many other investigators also indicated that the amount of protein, fat, ash and fibre are usually considered as an index of purity of legume starch (Lii \& Chang, 1981; Galvez \& Resurreccion, 1993). Reduction in ash, protein and amylose contents are due to structural disintegration that took place during chemical modification processes (hydroxypropylation).

The ash content is significantly correlated $(r=-0.959)$ with crude fat $(\mathrm{CF})$.Higher crude fat in the starches relate 
significantly with higher protein contents $(r=0.929)$ and lower NFE $(r=-0.448)$. Moisture content significantly correlated $(r=-0.896)$ with nitrogen free extract. $\mathrm{pH}$ and amylose were not significantly correlated to the other proximate components of the starch. However, Amylose and Amylopectin have a perfect negative correlation $(\mathrm{r}=$ - 1.000).

\subsection{Functional Properties of Native and Hydroxypropylated Water Yam Starches}

\subsubsection{Water Absorption Capacity (WAC) and Oil Absorption Capacity (OAC)}

Water and Oil absorption capacities of the hydroxypropylated water yam starches increased with the rise in molar substitution (Table 6).The WAC of the native and hydroxypropylated water yam starches ranged from $1.763 \mathrm{~g} / \mathrm{g}$ for native starch to $2.659 \mathrm{~g} / \mathrm{g}(12 \% \mathrm{HPS})$ in the order of $12 \% \mathrm{HPS}(2.659 \mathrm{G} / \mathrm{g})>10 \% \mathrm{HPS}(2.630 \mathrm{~g} / \mathrm{g})>$ $8 \%$ HPS $(2.259 \mathrm{~g} / \mathrm{g})>6 \%$ HPS $(2.207 \mathrm{~g} / \mathrm{g})>4 \%$ HPS $(2.062 \mathrm{~g} / \mathrm{g})>$ native starch $(1.763 \mathrm{~g} / \mathrm{g})$. WAC for native water yam starch is lower than the hydroxypropylated starches and there is significant difference in the WAC among the hydroxypropylated starches. Improvement in water and oil absorption was a result of introduction of hydroxypropyl groups to the starch molecules, which facilitated a more enhanced holding capacity. The increase in Water absorption capacity could also be due to some structural re-allignment exposing the hydrophilic end hence increased water absorption (Altan et al., 2009). Hydroxypropylation of banana starch has also been associated with increased water binding capacity, (Waliszewski et al., 2003). A similar pattern of result has been noted with acetylated sweet potato starches (Das AB et al., 2010). The ability of the starches to absorb water is a function of hydrophilic groups (-OH, $-\mathrm{COOH}$, inter-glucose oxygen atoms) available for binding with water (Otegbayo et al., 2011), amylose to amylopectin ratio, temperature, presence of phosphate-esters or protein, crystallinity and botanical source (Noda et al., 2008; Chen et al., 2003; Osundahunsi et al., 2003; Walter et al., 2000). High WAC is an indication of a loose association of starch polymers in the granules of the starches, while low WAC presumes close association of starch polymers in the starch granules (Shimelis et al., 2006). The increase in WAC on hydroxypropylation of water yam starch suggests weakened associative forces between the starch polymers in its granules ostensibly owing to the introduction of hydroxypropyl groups onto the starch polymers (Liu et al., (1999). Loosened starch structure due to the inhibition of inter-chain association facilitates the hydration of the starch granule arising from increased WAC. It has also been reported that there was increase in WAC of annealed African yam bean starch (Adebowale et al., 2009) and red sorghum starch (Adebowale et al., 2005).

Water absorption capacity of starch/flour is useful indicator of whether protein can be incorporated with the aqueous food formulations, especially, those involving dough handing (Osungbaro et al., 2010). Interactions of protein with water, plays a significant role in functional property of hydration, swelling power solubility, and gelation (Etudaiye et al., 2009). The high water absorption capacity of the flours suggests possible use in soup formulations (Olaofe et al., 1998). WAC is an important property in canned foods, confectioneries, pasta, and other cereal-based foods and hydroxypropylation evidently increased the WAC of the native water yam starch.

Oil absorption capacity ranged from $0.467 \mathrm{~g} / \mathrm{g}$ (native starch) to $1.417 \mathrm{~g} / \mathrm{g} 912 \% \mathrm{HPS}$ ), with significant variation among the hydroxypropylated starches (Table 6). The oil absorption capacity of the hydroxypropylated water yam starches increased marginally compared with native starch.The hydroxypropylated starches had similar oil absorption capacity as cassava $(1.57 \mathrm{~g} / \mathrm{g}$; Gunaratne, (2006) and lesser yam (Dioscorea esculenta) (1.9g/g; Ukpabi, 2010) but higher than raw fluted pumpkin flour (0.37g/g; Giami \& Bekebain, 1992). According to Lahl \& Braun (1994), lipid binding is dependent on the surface availability of hydrophobic amino acids. Oil absorption capacity is important as oil acts as flavor retainer and gives soft texture to food,thus improving mouth-feel (Aremu et al., 2006,Ubbor \& Akobundu, 2009;). Since the flours had good oil absorption capacity it suggests the presence of good lipophilic constituents and therefore may be suitable for production of sausage, soups and cakes (Aremu et al., 2006). Hydroxypropylation improved the oil absorption capacity probably as a result of higher density of lipophilic residues on the surface of its granules (Morrison et al., 1993). Citric acid modification slightly reduced the OAC of native white, water and bitter yam starches as against increase in OAC of citric-treated white yam flour (Akubor, 2013). Oil absorption capacity is an important property in fried foods, cooked foods, soups, pasta, and confectioneries.

The $\mathrm{pH}$ values is in the order of native (8.177) $>12 \%$ HPS $(6.877)>10 \%$ HPS $(6.58)>8 \%$ HPS $(6.510)>6 \%$ HPS (6.423) $>4 \%$ HPS (6.143) $6.877<$ for the native and hydroxypropylated starches. The highest $\mathrm{pH}$ was displayed by native water yam starch (8.177) while 4\%HPS starch gave the lowest (6.143) and the highest was $12 \%$ HPS(6.877) among the hydroxypropylated water yam starches. $\mathrm{pH}$ value is one of the physico-chemical properties of starch important to application.Similar observation has been reported for improved haricot bean by Shimelis et al., (2006). The $\mathrm{pH}$ values of the hydroxypropylated starches were found to be slightly lower than that 
of the native starch obviously because of the reaction with propylene oxide but it still falls within the $\mathrm{pH}$ range of 3-9 obtained for most starches used in the pharmaceutical, cosmetics and food industries.

Table 6. Water absorption capacity (WAC) and Oil absorption capacity (OAC) of native and hydroxypropylated water yam starch

\begin{tabular}{llll}
\hline Sample & WAC $(\mathrm{g} / \mathrm{g})$ & $\mathrm{OAC}(\mathrm{g} / \mathrm{g})$ & $\mathrm{pH}$ \\
\hline Native & $1.763 \pm 0.1$ & $0.467 \pm 0.0$ & $8.177 \pm 0.1$ \\
$4 \% \mathrm{HPS}$ & $2.062 \pm 0.1$ & $0.718 \pm 0.0$ & $6.143 \pm 0.0$ \\
$6 \% \mathrm{HPS}$ & $2.207 \pm 0.0$ & $0.868 \pm 0.0$ & $6.423 \pm 0.1$ \\
$8 \% \mathrm{HPS}$ & $2.259 \pm 0.0$ & $1.13 \pm 0.0$ & $6.510 \pm 0.0$ \\
$10 \% \mathrm{HPS}$ & $2.630 \pm 0.0$ & $1.355 \pm 0.0$ & $6.58 \pm 0.0$ \\
$12 \% \mathrm{HPS}$ & $2.659 \pm 0.0$ & $1.417 \pm 0.0$ & $6.877 \pm 0.1$ \\
\hline
\end{tabular}

Means in columns are significantly different at $5 \%$ level $(\mathrm{P}<0.05)$

\subsubsection{Least Gelation Capacity (LGC) of Native and Hydroxypropylated Water Yam Starch}

Modifying the native water yam starch resulted in lower LGC (2\%), thus enhancing their gelling capacity. This occurs with increase in molar substitution (Table 7), a phenomenon at variance with the report of Sung-Gil Choi (2001) on hydroxypropylation of wheat starch where gel hardness dipped significantly with increasing hydroxypropylation. This though compared favourably with the observation of Choi et al (1997) that of hydroxypropylation of high amylose corn starch which gave paste viscosity that was much less than that of native corn starch. The native water yam starch apparently developed soft viscous gels at lower concentrations, which became progressively hard as concentration increased.The gel network may have been closely linked to formation of intermittent hydrogen cross bonds among amylose and re-association of amylose molecules at random intervals (Vaclavik \& Christian, 2008). Hydroxypropylated water yam starches exhibited least gelation concentration at $2 \%$, a characteristic desired for thickener in food system, it could also be a useful replacement in viscous food formulation such as soups and baked foods. Gelatinization affects digestibility and texture of starch containing foods (Mweta, 2009).

Table 7. Least gelation concentration (LGC) of native and hydroxypropylated water yam starch

\begin{tabular}{|c|c|c|c|c|c|c|}
\hline Concentration (\%) & Native & $4 \%$ HPS & $6 \% \mathrm{HPS}$ & $8 \%$ HPS & $10 \%$ HPS & $12 \% \mathrm{HPS}$ \\
\hline 2 & V,SG(-) & $\mathrm{V}, \mathrm{SG}(+)$ & $\mathrm{HG}(+)$ & $\mathrm{HG}(+)$ & $\mathrm{F}, \mathrm{HG}(+)$ & $\mathrm{F}, \mathrm{HG}(+)$ \\
\hline 4 & $\mathrm{~V}, \mathrm{SG}(+)$ & $\mathrm{HG}(+)$ & $\mathrm{HG}(+)$ & $\mathrm{F}, \mathrm{HG}(+)$ & $\mathrm{F}, \mathrm{VHG}(+)$ & $\mathrm{F}, \mathrm{VHG}(+)$ \\
\hline 6 & $\mathrm{~V}, \mathrm{FG}(+)$ & $\mathrm{HG}(+)$ & F,HG(+) & $\mathrm{F}, \mathrm{HG}(+)$ & $\mathrm{F}, \mathrm{VHG}(+)$ & $\mathrm{F}, \mathrm{VHG}(+)$ \\
\hline 8 & $\mathrm{HG}(+)$ & $\mathrm{F}, \mathrm{HG}(+)$ & $\mathrm{F}, \mathrm{HG}(+)$ & $\mathrm{F}, \mathrm{VHG}(+)$ & $\mathrm{F}, \mathrm{VHG}(+)$ & $\mathrm{F}, \mathrm{VHG}(+)$ \\
\hline 10 & $\mathrm{~F}, \mathrm{HG}(+)$ & $\mathrm{F}, \mathrm{HG}(+)$ & $\mathrm{F}, \mathrm{HG}(+)$ & $\mathrm{F}, \mathrm{VHG}(+)$ & $\mathrm{F}, \mathrm{VHG}(+)$ & $\mathrm{F}, \mathrm{VHG}(+)$ \\
\hline 12 & $\mathrm{~F}, \mathrm{HG}(+)$ & $\mathrm{F}, \mathrm{HG}(+)$ & $\mathrm{F}, \mathrm{HG}(+)$ & $\mathrm{F}, \mathrm{VHG}(+)$ & $\mathrm{F}, \mathrm{VHG}(+)$ & $\mathrm{F}, \mathrm{VHG}(+)$ \\
\hline 14 & $\mathrm{~F}, \mathrm{HG}(+)$ & $\mathrm{F}, \mathrm{HG}(+)$ & $\mathrm{F}, \mathrm{VHG}(+)$ & $\mathrm{F}, \mathrm{VHG}(+)$ & $\mathrm{F}, \mathrm{VHG}(+)$ & $\mathrm{F}, \mathrm{VHG}(+)$ \\
\hline 16 & $\mathrm{~F}, \mathrm{HG}(+)$ & $\mathrm{F}, \mathrm{VHG}(+)$ & $\mathrm{F}, \mathrm{VHG}(+)$ & $\mathrm{F}, \mathrm{VHG}(+)$ & $\mathrm{F}, \mathrm{VHG}(+)$ & $\mathrm{F}, \mathrm{VHG}(+)$ \\
\hline 18 & $\mathrm{~F}, \mathrm{HG}(+)$ & F.VHG(+) & $\mathrm{F}, \mathrm{VHG}(+)$ & $\mathrm{F}, \mathrm{VHG}(+)$ & $\mathrm{F}, \mathrm{VHG}(+)$ & $\mathrm{F}, \mathrm{VHG}(+)$ \\
\hline LGC (\%) & 6 & 4 & 2 & 2 & 2 & 2 \\
\hline
\end{tabular}

V-viscous gel, F-firm gel, SG-soft gel, HG-hard gel, VGH-very hard gel, (+)-solid gel,(-)- no solid gel

\subsubsection{Swelling Power and Solubility of Native and Hydroxypropylated Starch}

Swelling power and solubility of the native and hydroxypropylated water yam starches are temperature dependent with swelling power increasing as the temperature rose from $50^{\circ} \mathrm{C}$ to $90^{\circ} \mathrm{C}$ (Table 8). The swelling power and solubility properties of the native and modified starches werelong been recognised as temperature and pH-dependent (Adebowale et al., 2005, Adebowale et al., 2009, Olayinka et al., 2011). Therefore, the increases in swelling power of hydroxypropylated starches can be attributed to the disruption of the amorphous region in the granule, which presumably reduced the restraining effect of amylose, thus allowing the granule to swell more freely (Karim et al., 2007).Liu et al. (1999) reported that hydroxypropylation increased the swelling power of starch with the soluble starch leaching out of the swollen granules on cooking. Swelling and solubility of starch vary with botanical source (Peroni et al., 2006). At $50^{\circ} \mathrm{C}$ and $60^{\circ} \mathrm{C}$ there was no significant change in the swelling power of the native starch probably because gelatinisation had not occurred, swelling power ranged from $2.045 \mathrm{~g} / \mathrm{g}$ to $2.085 \mathrm{~g} / \mathrm{g}$, the intermolecular micellar binding forces were still strong (Lorenz, 1990) and the crystalline regions of the starch granules were largely intact. Hydroxypropylated starches had the most 
favourable results for swelling power. The principal property of etherified starch is high water retention (Schmitz et al., 2005).Native starch presented inferior values for swelling power compared to hydroxypropylated water yam starches. This is in agreement with Kaur et al. (2004), who studied hydroxypropylated potato starch in comparison with native starch's physical chemistry properties. The values for the hydroxypropylated starches ranged from $2.814 \mathrm{~g} / \mathrm{g}$ (4\%HPS) to $4.187 \mathrm{~g} / \mathrm{g}(12 \% \mathrm{HPS})$ and $3.151 \mathrm{~g} / \mathrm{g}$ (4\%HPS) to $7.307 \mathrm{~g} / \mathrm{g}$ (12\%HPS).The native starch had the lowest Swelling Power at $50{ }^{\circ} \mathrm{C}$ and $60^{\circ} \mathrm{C}$ while $12 \%$ HPS had the highest Swelling Power (SP). The high value for $12 \%$ HPS could be as result of highest volume of propylene oxide used for the modification which contributed to the highest MS value. Increased MS values of hydroxypropylated starch derivatives are positively correlated with solubility and swelling power (Gunaratne \& Corke, 2007;Lawal, 2009). The swelling power $(35.5-52.8 \mathrm{~g} / \mathrm{g})$ and solubility $(8.19-10.7 \%)$ values of the hydroxypropylated rice starches were higher than those of native rice starch $(26.6 \mathrm{~g} / \mathrm{g}$ and $7.78 \%)$ and increased with an increase in MS (Chun \& Yoo, 2007).

As the temperature increased from $70^{\circ} \mathrm{C}$ to $80^{\circ} \mathrm{C}$, there was an increase in swelling power of the hydroxypropylated starches in this order: 4\%HPS $<6 \% \mathrm{HPS}<8 \% \mathrm{HPS}<10 \% \mathrm{HPS}<12 \% \mathrm{HPS}$ and is proportional to their individual molar substitution. The implication of this is that for each temperature there was a rise in the swelling power of the starches for every $2 \%$ increase in propylene oxide. Swelling power (SP) and solubility can be used to assess the extent of interaction between starch chains, within the amorphous and crystalline domains of the starch granule (Ratnayake, et al., 2002).

It can be inferred that these changes are attributed to the relative ease at which inter-molecular bonds are interrupted and its rise associated in entropy (Odeku \& Picker-freyer, 2007), increased mobility of starch molecules resulting in increased percolation of water (Lawal et al., 2005), and overriding high energy required to break such bonds at the higher temperature of $80^{\circ} \mathrm{C}$. As a result, the crystalline regions of the starches become relatively accessible for water molecules to bind, thus effectively swelling. Starch ether production and starch hydroxypropylation improve the starch's water retention capacity, because of intermolecular bond established between the water molecules and the starch macromolecule new sites. The native water yam starch had significantly lower SP than their hydroxypropylated water yam starches at $80^{\circ} \mathrm{C}$. The restricted swelling of native starch may be due to increased crystallinity as a result of preferential hydrolysis of amorphous regions (amylose), and less importantly, crystalline regions (amylopectin), as reported for cassava starch (Chatakanonda et al., 2011), hybrid maize starch (Lawal et al., 2005) and sweet potato starch (Olorunsola et al., 2011, Mweta, 2009).

At $90^{\circ} \mathrm{C}$, swelling power ranged from $6.143 \mathrm{~g} / \mathrm{g}$ (native starch) to $10.904 \mathrm{~g} / \mathrm{g}(12 \% \mathrm{HPS}$ ) within the temperature range studied $\left(50-90^{\circ} \mathrm{C}\right)$, SP were temperature dependent and highest SP in each case was obtained at $90{ }^{\circ} \mathrm{C}$. Progressive increases were observed as the temperature increased and it was observed that hydroxypropylation improved the SP of the native water yam starch at all temperatures. This is similar to the observation on hydroxypropylation of finger millet (Lawal, 2009). Increases in swelling power after hydroxypropylation were facilitated by introduction of the bulky hydroxypropyl groups into the starch molecules. These caused repulsion among the molecules, thereby facilitating water percolation into the granules. It is also reasonable to conclude that the introduction of the hydrophilic hydroxypropyl groups improved water percolation into the starch and this improved swelling remarkably. Similar increases in swelling capacity following hydroxypropylation have been reported for wheat starch, banana and potato starch (Hung \& Morita, 2005; Waliszewski et al., 2003).

Among the hydroxypropylated starches 12\%HPS had the highest SP value which could be attributed to its highest value for MS as earlier mentioned, lowest value for protein, lipids, and the amylose content. High swelling and low WBC has been linked to starches with low amylose content since amylose reinforces internal network within granules thus restricting swelling (Tester \& Morrison 1990). Swelling power has also been reported to increase with increasing long chains of amylopectin and decreasing amylose content (Sasaki \& Matsuki, 1998). Amylose in the presence of lipids forms insoluble complexes limiting swelling and solubility of the starch (Tester \& Karkalas, 1996). It is widely believed that lipid complexed with amylose restricts granule swelling (Tester \& Qi, 2004).Among the other factors that have been shown to influence granular swelling are granular size (Vasanthan \& Bhatty, 1996), crystallinity ,temperature,amount of phosphate linked to amylopectin (Jane et al., 1996 ), amylose content (Tester \& Morrison, 1990a), protein (Han \& Hamaker, 2002; Han et al., 2002).

The swelling power and solubility of the hydroxypropylated starches were higher than the native starch. Progressive increase in swelling power and solubility were observed as the MS increased among the hydroxypropylated starches. (Naknaen, 2014, Lawal, 2008), Liu et al., (1999) reported that hydroxypropylation increased the swelling power of starch and the soluble starch which leach out of the swollen granules on cooking. This is in agreement with Oladebeye et al., (2013) in the hydroxypropylation of legume starches, who reported 
that the values of swelling power, solubility of the native starches were significantly different from the hydroxypropyl derivatives. Hydroxypropylation apparently enhanced the free swelling capacity (FSC) and solubility as reported by Lawal et al., (2008) in the hydroxypropylation of white yam. . Hydroxypropylation resulted in a significant increase in swelling of granules, especially between $70^{\circ} \mathrm{C}$ and $90^{\circ} \mathrm{C}$, since the hydroxypropyl groups replaced the original $-\mathrm{OH}$ groups and allowed easier access of water molecules into the starch granules (Mweta,2009).At all temperatures, the swelling of hydroxypropylated starches were higher than the native water yam starch. Swelling and solubility provide evidence of non-covalent bonding between starch molecules and therefore allow comparison of relative bond strength at specific temperatures (Moorthy, 2002). The extent of interaction between starch chains within the amorphous and crystalline domains is influenced by the amylose to amylopectin ratio, and by the characteristics of amylose and amylopectin in terms of molecular weight/distribution, degree and length of branching and conformation (Hoover, 2001). When the starch molecules are heated in excess water, their crystalline structure is disrupted and water molecules become linked to the exposed hydroxyl groups of amylose and amylopectin by hydrogen bonding, which causes an increase in granule swelling and solubility (Singh, 2004).

Solubilities of native and hydroxypropylated starches were also temperature dependent (Table 8). At $50^{\circ} \mathrm{C}$ to $60^{\circ} \mathrm{C}$ when gelatinization had probably not fully occurred, solubility ranged from $3.172 \mathrm{~g} /$ (native starch) to $5.841 \mathrm{~g} / \mathrm{g}\left(12 \% \mathrm{HPS}\right.$ ) and $3.908 \mathrm{~g} / \mathrm{g}$ (native starch) to $6.037 \mathrm{~g} / \mathrm{g} 912 \% \mathrm{HPS}$ ) respectively. However at $70^{\circ} \mathrm{C}$, when partial gelatinization may have occurred and the starches had imbibed water considerably, solubility generally increased in all starches, ranging from $4.20 \mathrm{~g} / \mathrm{g}$ native starch to $7.206 \mathrm{~g} / \mathrm{g}$ (12\%HPS). This may be attributed to structural reorganization, which tends to weaken the starch granules following hydroxypropylation and ranked in this order: $12 \%$ HPS $>10 \%$ HPS $>8 \%$ HPS $>6 \%$ HPS $>4 \%$ HPS $>$ native starch. Solubility also increased as the level of modification increased from 4\%HPS to 12\%HPS. It is reasonable that increase in starch hyrophilicity after hydroxypropylation facilitated water percolation into the starch granules. Increase in water percolation enhanced leaching of amylose granules largely from the amorphous region of the starches.

Solubility of the hydroxypropylated water yam starches increased significantly at $80^{\circ} \mathrm{C}$ and $90^{\circ} \mathrm{C}$ (in the order of native starch $<4 \%$ HPS $<6 \%$ HPS $<8 \%$ HPS $<10 \%$ HPS $<12 \%$ HPS). At this time full gelatinization had occurred probably owing to increased levels of total soluble sugars (reducing and non-reducing) resulting emanating from partial hydrolysis (Manuel, 1996). Slight reduction in the polymeric nature of the amorphous and crystalline regions of the starches during hydroxypropylation may also have provided better access for water molecules to penetrate the almost-impregnable amorphous and crystalline regions of the native starches, thereby enhancing solubility. In addition, inter- and intra molecular hydrogen bonds in the starch chains were disrupted, the granular structure of the starches were weakened and the motional freedom of starch chains increased as the temperature increased. This facilitated increases in solubility of the starch as observed. The extent of swelling is positively related to the solubility, i.e., the higher the swelling power, the greater the solubility. The increases in swelling after hydroxypropylation could be put to advantage in starch applications such as food thickening and preparation of hydrogels. Thus, swelling and solubility of starch is temperature dependent, increasing with increasing temperature due to weakening of internal associative forces maintaining the granular structure (Peroni et al., 2006).Starch swelling occurs concomitantly with loss of birefringence and precedes solubilisation (Singh et al., 2004). Solubility of native and hydroxypropylated water yam starches were temperature dependent (Table 8). Solubility also increased as the level of modification increased from 4\%HPS -12\%HPS. It is reasonable that increase in starch hyrophilicity after hydroxypropylation facilitated water percolation into the starch granules and the increase in water percolation enhanced leaching of amylose granules largely from the amorphous region of the starches. In addition, inter and intra molecular hydrogen bonds in the starch chains are disrupted, hence the granular structure is weakened and the motional freedom of starch chains increases as the temperature increases thus improving solubility (Lawal, 2009).Similar result was reported by Lawal, (2009) in the hydroxypropylation of finger millet where solubility were temperature dependent and solubility increased as the level of modification increased. The solubility of the starches exhibited similar pattern to that of swelling power and differed significant $(\mathrm{P}<0.05)$ among the hydroxypropylated starches.

All the hydroxypropylated starch derivatives exhibited greater solubility and swelling power than native starch. It is commonly known that incorporation of bulky, hydrophilic hydroxypropyl groups into starch molecules within granules prevents inter-chain association among starch molecules, leading to destabilization of starch granule structures. The loosened granules facilitate hydration, and thus, enhance granule swelling, which further results in an increase in leaching of hydroxypropylated starch molecules from swollen granules (Gunaratne \& Corke, 2007; Lawal, 2009, Singh et al., 2007). 
Table 8. Swelling Power and Solubility of native and hydroxypropylated water yam starch

\begin{tabular}{lllllllllll}
\hline Sample & \multicolumn{2}{l}{ Swelling Power $(\mathrm{g} / \mathrm{g})$} & \multicolumn{7}{c}{ Solubility $(\mathrm{g} / \mathrm{g})$} \\
\hline & $50^{\circ} \mathrm{C}$ & $60^{\circ} \mathrm{C}$ & $70^{\circ} \mathrm{C}$ & $80^{\circ} \mathrm{C}$ & $90^{\circ} \mathrm{C}$ & $50^{\circ} \mathrm{C}$ & $60^{\circ} \mathrm{C}$ & $70^{\circ} \mathrm{C}$ & $80^{\circ} \mathrm{C}$ & $90^{\circ} \mathrm{C}$ \\
\hline Native & $1.545 \pm 0.0$ & $3.585 \pm 0.1$ & $5.579 \pm 0.0$ & $6.05 \pm 0.1$ & $6.143 \pm 0.1$ & $3.172 \pm 0.0$ & $3.908 \pm 0.1$ & $4.201 \pm 0.1$ & $5.23 \pm 0.2$ & $4.863 \pm 0.1$ \\
$4 \%$ HPS & $1.814 \pm 0.0$ & $3.751 \pm 0.1$ & $6.278 \pm 0.1$ & $7.314 \pm 0.1$ & $7.898 \pm 0.3$ & $3.841 \pm 0.0$ & $4.037 \pm 0.1$ & $4.814 \pm 0.0$ & $5.862 \pm 0.1$ & $5.048 \pm 0.1$ \\
$6 \%$ HPS & $2.904 \pm 0.0$ & $3.692 \pm 0.1$ & $6.924 \pm 0.1$ & $7.863 \pm 0.1$ & $8.051 \pm 0.1$ & $4.171 \pm 0.0$ & $4.695 \pm 0.0$ & $5.100 \pm 0.1$ & $6.143 \pm 0.1$ & $5.926 \pm 0.1$ \\
$8 \%$ HPS & $3.140 \pm 0.1$ & $3.952 \pm 0.3$ & $7.729 \pm 0.0$ & $9.478 \pm 0.6$ & $10.035 \pm 0.1$ & $4.870 \pm 0.0$ & $5.206 \pm 0.0$ & $5.763 \pm 0.2$ & $8.667 \pm 0.1$ & $6.720 \pm 0.0$ \\
$10 \%$ HPS & $3.960 \pm 0.1$ & $5.242 \pm 0.2$ & $8.224 \pm 0.4$ & $9.852 \pm 0.1$ & $10.362 \pm 0.2$ & $5.276 \pm 0.1$ & $5.909 \pm 0.1$ & $6.202 \pm 0.2$ & $9.271 \pm 0.2$ & $8.166 \pm 0.0$ \\
$12 \%$ HPS & $4.187 \pm 0.0$ & $7.307 \pm 0.1$ & $9.594 \pm 0.1$ & $10.193 \pm 0.0$ & $10.904 \pm 0.4$ & $5.841 \pm 0.2$ & $6.037 \pm 0.1$ & $7.206 \pm 0.2$ & $9.796 \pm 0.0$ & $8.901 \pm 0.1$ \\
\hline
\end{tabular}

Means in columns are significantly different at $5 \%$ level $(\mathrm{P}<0.05)$

\subsubsection{Starch Gel Clarity (SGC)}

Gel clarity ranged from $8.8 \%$ (native starch) to $44.5 \%$ (12\%HPS) as inferred from their transmittance (Fig.2).The clarity increased with increase in MS having the 4\%HPS with the lowest value for clarity among the hydroxypropylated starches while the native starch had the lowest value compared to the modified starches. In literature, light transmittance of potato starch, corn and amaranth starch increased after hydroxypropylation (Pal et al., 2000, Kaur et al., 2004 and Singh et al., 2004a) and this suggests reduction in paste turbidity. In addition, paste clarity of normal and waxy maize starches also increased after hydroxypropylation (Liu et al., 1999). Substitution of the hydroxyl groups with hydroxypropyl groups on the starch molecules prevented reformation of inter and intra-molecular bonds after paste formation. These development improved paste clarity and prevented turbidity of the starch paste. Improved paste clarity is a useful property in the manufacture of some foods like jellies, sausages and fruit pastes, which require transparency (Jyothi, et al., 2005). The chemical substitution of the $-\mathrm{OH}$ groups on the starch molecules by hydroxypropyl moieties hampers the formation of an ordered structure following gelatinization, and thus retards retrogradation, resulting in a more fluid paste with improved long-term clarity (Lawal, 2004). The high retention of water entering the starch granule results in a greater swelling power and favours the clarity of pastes and gels. Reduced swelling of native water yam starch is mainly responsible for its reduced paste clarity; a conclusion that is in agreement with similar studies; Zheng et al., 1999 , Morikawa \& Nishinari, 2000a; Reddy \& Seib, 2000 and Kaur et al., 2006,. Starches used to thicken fruit pies are preferably transparent while those in salad dressings are opaque.

As shown in figure 2, native water yam starch had the lowest clarity just like other functional properties of starch, varies with its source (Tetchi et al., 2007b; Singh et al., 2003).There is a great variation in gel turbidity after gelatinization of starch, as well as the changing pattern among diverse species and within the same species during storage (Amani et al., 2005; Otegbayo et al., 2014).Compared with potato and cassava starches, yam starches from diverse species had higher gel turbidity (Amani et al., 2005).Potato starches have higher paste clarity $(96 \% \mathrm{~T})$ than corn $(31 \% \mathrm{~T})$, wheat $(28 \% \mathrm{~T})$ and rice (24\%).Mweta, (2009).compared clarity of potato, tapioca, wheat, and corn starch pastes among others. They reported higher paste clarity for potato (96\% T), than for tapioca $(73 \% \mathrm{~T})$, wheat $(62 \% \mathrm{~T})$ and corn $(41 \% \mathrm{~T})$ starches. Tetchi et al. (2007b) also found that potato starch pastes were more transparent $(79 \% \mathrm{~T})$ than cassava $(47 \% \mathrm{~T})$, sweet potato $(17 \% \mathrm{~T})$ and cocoyam $(16 \% \mathrm{~T})$ starch pastes. These differences in paste clarity have been attributed to differences in chemical composition such as phosphate and amylose. Potato starch pastes have higher paste clarity than cereal starches due to high content of phosphate monoesters as opposed to higher contents of phospholipids in cereal starches. Phospholipids present in starches form complexes with amylose and long chain fractions of amylopectin resulting in limited swelling and hence lower light transmittance. On the other hand, phosphate monoesters covalently bond to amylopectin fraction and due to repulsions between phosphate groups on adjacent amylopectin groups swelling is enhanced and hence light transmittance (Singh et al., 2003). Amylose reorganisation forms aggregates that reduce light transmittance of starch pastes (Tetchi et al., 2007b). High amylose starches reassociate more readily than amylopectin starches thereby resulting in more opacity (Bultosa et al., 2002). Paste clarity was related to amylose content, because native water yam starch presented the most opaque gel and the highest amylose content. This observation compares favourably with native and hydroxypropylated cassava starch (Schmitz et al., 2005) Paste clarity is valued in starch applications such as food additives because it enhances consumer acceptability of the product, particularly those products that could stay on shelf for a long time. Examples of such products are jellies, sausages, and fruit pastes. It is reasonable that inter- and intra-molecular repulsion among the bulky hydroxypropyl groups is responsible for the enhanced paste clarity after modification. In previous work, it was also reported that carboxymethylation of starch improved starch paste clarity (Lawal et al., 
2007). Similarly, light transmittance of potato starch, corn amaranth and cassava starches increased after hydroxypropylation. (Pal et al., 2002; Kaur et al., 2004; Jyothi et al., 2007).

Starch gel clarity seems to be directly related to the solubility (especially at $80^{\circ} \mathrm{C}$ and $90^{\circ} \mathrm{C}$ ) of the starches where the amylose content of starches has a bearing on its ability to solubilise in water. Similar observation was made by Takizawa et al., (2004) for starches of potato, sweet potato and cassava, whose paste clarity increased with oxidative modification and related to their solubility. There were significant differences in gel clarity between native and hydroxypropylated water yam starches. Water yam starch has good gel clarity, though, comparatively pale to that of cassava starch (Betancur-Ancona et al., 2003). The clarity of a starch gel directly influences the sheen and colour of products that contain them as thickener (Betancur-Ancona et. al., 2003).

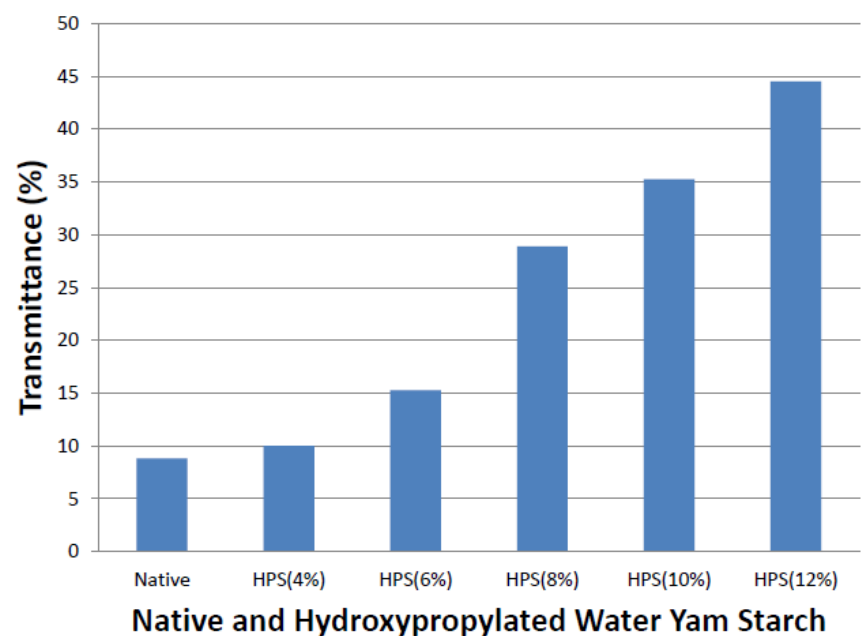

Figure 2. Starch gel clarity of native and hydroxypropylated water yam starch

\subsubsection{Emulsion Capacity (EC) and Relative Occluded Volume (ROV)}

Emulsion capacity of the native and hydroxypropylated water yam starches ranged from $16.91 \%$ (native starch $12 \%$ HPS) to $51.13 \%$ (native starch) as shown in Table 9. The 12\%HPS had the highest emulsion capacity and relative occluded volume-functional properties which reduced with increase in molar substitution .This reflects a potential to form better oil-water interface, and hence better hydrophobicity (Adebowale et al., 2009). This is in agreement with the report from oxidation of acha starch by Isah et al., (2015) that oxidation improved the water and oil absorption capacity of the native acha starch and also the emulsion capacity was significantly improved .The emulsion capacity were in the order of 12\%HPS $(51.13 \%)>10 \%$ HPS $(47.59 \%)>8 \%$ HPS $(33.702 \%)>6 \%$ HPS $(27.71 \%)>4 \%$ HPS $(16.962 \%)>$ native starch $(16.909 \%)$. There was significant difference $(\mathrm{P}<0.05)$ in the emulsion capacity of the starches. The $4 \%$ concentration of propylene oxide did not have a significant effect on the emulsion capacity of the native starch until when the concentration increased to $6 \%$.The higher the concentration the better the emulsion capacity. High emulsion characteristic are an indication that the flour sample is an excellent emulsifier in various foods (Berger, 1997). Emulsion capacity of the hydroxypropylated water yam starches were superior to that of native starch and increased as modification level increased.

Oil absorption capacity of the starches correlated significantly with water absorption capacity $(r=0.979, \mathrm{P}<0.01)$ which is an indication that the starches generally had hydrophilic and hydrophobic groups that can absorb water or oil onto its structure matrices. OAC is strongly significantly correlated $(\mathrm{r}=-0.849, \mathrm{P}<0.05)$ with $\mathrm{LGC}$ as well as WAC $(r=-0.840)$.At all temperature, solubility is significantly correlated $(r=0.991,0.984,0.964,0.967$, and $0.974)$ to WAC as well as OAC $(r=0.968,0.963,0.947,0.957,0.91)$. Starches in suspension form gel at elevated temperatures as a result of amylose fractions leaching, and swelling brought about by amylopectin fractions, thus leading to increasing ability of the starches to absorb water (Mweta, 2009). Gel clarity of starches is high when starch suspensions are fully gelatinized, which involves amylose solubilization and amylopectin swelling, hence the high significant relationships of starch gel clarity (SGC) and $\mathrm{SP}$ at $80^{\circ} \mathrm{C}$ and $90^{\circ} \mathrm{C}(\mathrm{r}=0.986,0.983, \mathrm{P}<0.01)$; and SGC and solubility at $80^{\circ} \mathrm{C}$ and $90^{\circ} \mathrm{C}(\mathrm{r}=0.986,0.983)$. There was strong significant correlation between OAC and the ability of the starch to form emulsion $(r=0.967, \mathrm{P}<0.01)$, WAC $(r=0.957)$ and SGC $(r=0.977)$ but insignificant to LGC of the starches. 
A strong correlation was observed at swelling power of $50^{\circ} \mathrm{C}(\mathrm{r}=0.983)$ with emulsion capacity when full gelatinization had not taken place, this implies that most starch emulsions are unstable at higher temperatures. Swelling power and solubility of the starches correlated significantly regardless of the temperatures effects and all there is strong association between the functional properties which were all significantly correlated positively except least gelation concentration.

Table 9. Emulsion capacity and Relative occluded volume of native and hydroxypropylated water yam starch

\begin{tabular}{lll}
\hline Sample & Emulsion capacity $(\%)$ & Relative occluded volume (v/v) \\
\hline Native & $16.909 \pm 0.8$ & $0.175 \pm 0.0$ \\
$4 \%$ HPS & $16.962 \pm 0.3$ & $0.203 \pm 0.0$ \\
$6 \%$ HPS & $27.71 \pm 0.3$ & $0.215 \pm 0.0$ \\
$8 \%$ HPS & $33.702 \pm 0.3$ & $0.311 \pm 0.0$ \\
$10 \%$ HPS & $47.59 \pm 0.18$ & $0.380 \pm 0.0$ \\
$12 \%$ HPS & $51.13 \pm 0.7$ & $1.046 \pm 0.0$ \\
\hline
\end{tabular}

Means in columns are significantly different at $5 \%$ level $(\mathrm{P}<0.05)$

\subsubsection{Pasting Properties of Native and Hydroxypropylated Starch}

Real-time viscosity measurements at constant shear and regulated temperature change rates undergone in a heating, holding and cooling pattern/profile for starches can reveal shear, stress and other tensile properties of a starch paste. The pasting properties of the native and hydroxypropylated water yam starches and their significant differences are presented in Table 10.The pasting profile is as shown in figure 3. Agronomic practices have a great influence on the pasting properties of starch. Harvesting time has been linked to the pasting of yam starch (Huang et al., 2006; P'erez et al., 2011; Akinoso \& Abiodun, 2013). Peak viscosity of the native water yam starch was 583.63RVU while peak viscosity for the hydroxypropylated starches ranked in the order of 8\%HPS $(571.17 \mathrm{RVU})>12 \% \mathrm{HPS} \quad(505.29 \mathrm{RVU})>4 \% \mathrm{HPS} \quad(454.54 \mathrm{RVU})>10 \% \mathrm{HPS} \quad(450.92 \mathrm{RVU})>6 \% \mathrm{HPS}$ (297.83RVU). Peak Viscosity for the native starch was the highest (583.63RVU), this is higher than values from Ji et al., (2003) who reported PV in the range between 152 and 222 RVU for selected corn lines. A report from Oke et al. (2013) gave values for Peak Viscosity and Final Viscosity, Pasting Temperature as 400.92RVU and 504.08RVU, $80.38-86.15^{\circ} \mathrm{C}$, respectively for native water yam starches, the difference may be attributed to the cultivar. Peak viscosity of starches from D. alata, D. rotundata, D. cayenensis, and D. Dumetorum (1 genotype for each) ranged from 2028 to $3893 \mathrm{mPa}$ (Farhat et al.,1999). PV of starches from 27 genotypes of $D$. Rotundata ranged from 177RVU to 524RVU (Otegbayo et al D. Dumetorum (1 genotype for each) ranged from 2028 to $3893 \mathrm{mPa}$ (Farhat et al., 1999). PV of starches from 27 genotypes of D. Rotundata ranged from al., 2014).Among the hydroxypropylated starches $8 \%$ HPS had the highest peak viscosity, all the hydroxypropylated starches had lower Peak Viscosity compared to the native starch and they are all significantly different. The higher peak viscosity exhibited by native starch in this study was due to higher granule rigidity and integrity, associated with the presence of amylose (Karim et al., 2007).Variations in Peak Viscosity was observed for the modified starches and this in agreement with Kaur et al., (2004), who reported that hydroxypropylated starches present variations in PV property because of a granular associative force reduction. This is at variance with Choi et al., (1997) who reported that peak viscosity of hydroxypropylated corn starch increased with increase in the degree of substitution.The reduction in viscosity of hydroxypropylated starch upon cooling is related to its amylose content. However, this justification does not apply with regard to the modified starches, which show low viscosity upon cooling and low amylose content in comparison with native starch (Table 5). This performance may have occurred because of the increase in associative forces within the native starch granules that resulted in decreased penetration of water (Schmitz et al., 2005). This is in contrast with cassava starch (Chatakanonda et al., 2011, Jyothi et al., 2011), fermented cassava starch (Gomes et al., 2004b) and the increasing peak viscosity of starch may be linked to increasing granule size (Huang et al., 2006). This reduction may be due to hydroxypropylation treatment tightening the connections among the molecules of starch, making them to assume a more stable could be because the amorphous region (likely containing amylose) was not disrupted by treatment, thus the granular structure was not weakened. Consequently, when shear was applied to the starches during pasting, the granules could attain their maximum swelling capacity, resulting in increase of the peak viscosity.The decrease in peak viscosity observed in hydroxypropylated water yam starch could be related to the presence/absence of surface proteins (Han \& Hamaker, 2002). The protein on the surface of the starch granule would be partially removed when treated with propylene oxide (Han \& Hamaker, 2002).This premise is supported by our protein determination, which showed that the protein content for hydroxypropylated 
starches decreased significantly compared to that of native corn starch (Table 5). This native starch may find application in foods requiring high viscosity. Native starch and hydroxypropylated starches showed significantly distinct viscosity characteristics, which determine their possible industrial applications.

The native water yam starch had the highest trough viscosity (508.96RVU) and breakdown viscosity of 896cp, significant differences were observed among the starches (native and hydroxypropylated. An increase in breakdown viscosity was observed at $8 \% \mathrm{HPS}(312.75 \mathrm{RVU})$ to $12 \% \mathrm{HPS}(115.67 \mathrm{RVU})$. Trough viscosity (TV) is the lowest viscosity attainable in the isothermal phase of the viscosity profile; while the breakdown viscosity (BV) is the deduction of trough viscosity from peak viscosity, as a measure of the susceptibility of a starch paste to disintegrate and lose viscosity during the high temperature holding phase (Han \& Hamaker, 2002).Breakdown is a measure of the response of starch pastes to shear-thinning during the holding period at $95{ }^{\circ} \mathrm{C}$ (Lai $e t$ al., 2004). Thus, breakdown viscosity indicates the tendency of starch to resist shear force during heating (Karim et al., 2007). Shi \& BeMiller (2000), and Pal et al., (2002) reported that hydroxypropylated corn starch showed increased shear breakdown because the susceptibility of swollen starch granules to prolonged stirring was increased by the modification. This is in agreement with Han et al., (2004) for hydroxypropylated waxy rice and corn starches which showed lesser BV compared to the native starches. The reason is unclear, but we presume that the absence of amylose in the waxy starches tested might have produced different shear-thinning results (Han et al., 2004).Among the hydroxypropylated starches, only 8\%HPS was highly shear thinning while 6\%HPS was slightly shear thinning. Others (native 10\%HPS and 12\%HPS) are moderately shear thinning. Degree of shear thinning is a property that may be harnessed in enhancing heat transfer in canned foods and as suspension aids. The 6\%HPS had the lowest breakdown viscosity, hence the higher the breakdown in viscosity, the lower the ability of the sample to withstand heating and shear stress during cooking (Adebowale et al., 2005). Breakdown values were significantly higher $(\mathrm{p} \leq 0.05)$ for $8-12 \%$ HPS starches which is an indication that the granules were not strong and did not resist breakdown under shear and heat, a result also noted by Singh et al., (2006). Low breakdown coupled with high viscosity is a desirable property of starch because its paste has a non-cohesive texture suitable for many food and industrial applications.

The final viscosity (FV) of the starches ranged from 811.63RVU to 303.92RVU, with the lowest values observed in $8 \%$ HPS and the highest found in native starch. The final viscosity (FV) is the viscosity after holding cooked starch at the cooling phase. It is a crucial parameter used to define the quality of starch-based foods as it indicates the ability of the material to form a viscous paste or gel after cooking and cooling and its resistance to shear force during stirring (Adebowale et al., 2008). According to commonly observed pasting properties of hydroxypropylated starches (Chuenkamol et al., 2007; Gunaratne \& Corke, 2007; Jyothi et al., 2007; Lawal, 2009; Liu et al., 1999), the enhanced hydration and swelling of starch granules via starch hydroxypropylation result in rapid viscosity development and the increased peak viscosity (corresponding to the increase in breakdown viscosity) of the starch paste. Also, bulky substituent restricts inter-chain association, leading to reduced final viscosity (associated with decreased setback viscosity) (Chung et al., 2010)

The setback viscosity (SV) is the increase in viscosity of the starch paste during the cooling phase of pasting. It's the deduction of trough viscosity from final viscosity and represents the ability of the swollen solubilised granules to re-associate, a feature more commonly linked to amylose than amylopectin. Setback reflects the retrogradation tendency of starch upon cooling (Zaidul et al., 2003) i.e. increase in viscosity of starch pastes during cooling indicates propensity of the various granules (swollen intact and broken granules, colloidal dispersions, and dissolved molecules) to retrograde as temperature of the paste decreases (Adebowale et al., 2009).

The SV among the hydroxypropylated starches ranked in the order of 4\%HPS > native $>12 \%$ HPS $>6 \%$ HPS $>10 \%$ HPS $>8 \%$ HPS. Setback viscosity reduced after hydroxypropylation, this is in agreement with the report on hydroxypropylation of white yam, Dioscorea rotundata (Lawal et al.,2008).The native water yam starch showed a higher tendency to regain viscosity during cooling than the native starches do, thus having significantly higher SV, and may be more susceptible to retrogradation as the swollen solubilised starch which were earlier leached out tend to re-associate again, re-establishing a highly ordered network of increased intermolecular bonding between the molecules. Similar discoveries were made for African yam bean (Adebowale et. al., 2009); fermented cassava starch (Gomes et al., 2004b); and red sorghum starch (Adebowale et al., 2005). The setback is more pronounced at lower concentrations (4\%HPS) than higher concentrations (6-12\%HPS) water yam starch. The bulky hydroxypropyl groups introduced during the modification prevented the structural realignment of leached amylose molecules after gelatinization (Lawal, 2008), thus minimizing retrogradation. This is compares favourably with findings of Lee \& Loh, (2011) in the hydroxypropylation of babana starch, during which decrease of setback values in hydroxypropylated starch was observed with 
increasing of MS. For the hydroxypropylated water yam starches, it is as a result of steric effects imposed by the bulky hydroxypropyl groups which inhibit proper alignment of starch chains during chain aggregation and crystallization (Perera \& Hoover, 1999), thus facilitating lower setback values and tendency to retrograde (Betancur-Ancona et al., 1997; Yu et al., 2005).It may also be as a result of weakening of intermolecular interactions between amylose molecules thus hindering realignment of the molecules. Besides, the presence of low molecular weight sugars tend to bind up more moisture (necessary for furnishing hydrogen and hydroxyl ions) that would have been otherwise available for amylose molecules to form strong re-associating hydrogen bonds between one another (Yu et al., 2005).Setback of the native water yam starch was found to decrease when starches were hydroxypropylated (Wattanachant et al., 2002).Pasting temperature was recorded when the rate of change of viscosity above the set point was first achieved (Jin-song, 2008), which indicates the onset gelatinization temperature of the starch. Pasting temperature decreased with increase in MS, it ranked as native $\left(84^{\circ} \mathrm{C}\right)>4 \%$ HPS $\left(84.1^{\circ} \mathrm{C}\right)>6 \%$ HPS $\left(81.3^{\circ} \mathrm{C}\right)>8 \%$ HPS $\left(79.5^{\circ} \mathrm{C}\right)>10 \% \mathrm{HPS}\left(81.95^{\circ} \mathrm{C}\right)>12 \% \mathrm{HPS}\left(81.93^{\circ} \mathrm{C}\right)$ and they were all significantly different. Hydroxypropylation reduced the pasting temperature, this is in agreement with Choi, et al., (1997) in the hydroxypropylation of corn starch, Lee and Yoo (2011) (banana starch hydroxypropylation) and Phisut Naknaen (2014) in the hydroxypropylation of jackfruit seed starch. The high pasting temperature of native starch indicated its higher resistance towards swelling. Seetharaman et al., (2001) reported pasting temperatures in the range of $74.9-84.7^{\circ} \mathrm{C}$ for Argentinian corn landraces. Hydroxypropyl groups are hydrophilic in nature and when introduced into starch granules, weaken the internal bond structure holding the granule together, leading to an increase in accessibility of starch granules to water. This reduction in bond strength is reflected in starch pasting temperature .Peak time reduced significantly after hydroxypropylation except at $6 \%$ HPS that a sharp increase was observed. The time required to cook the starch paste to the peak viscosity, the peak time (PkT), ranged from 7 mins (native starch) to 4.467 minutes which implies that they are not difficult to cook to peak viscosity. Hydroxypropylated starches have hydrophilic surface activity, making their surface easily accessible to hot liquor, a factor attested to by their high solubility.

Pasting temperature of the starches correlated significantly with peak time $(r=0.953, P<0.01)$ similar to that reported for starches of lesser yam, water yam, elephant yam, new cocoyam, kudzu, sweet potato, sago, taro, arrow root and cassava (Srichuwong et al., 2005).Trough viscosity and final viscosity were significantly correlated $(\mathrm{r}=0.938)$. Breakdown viscosity was positively correlated with the pasting temperature $(\mathrm{r}=0.900)$. Kaur et. al., (2006) reported negative correlation of Breakdown viscosity with Pasting Temperature.

Table 10. Pasting properties of native and hydroxypropylated water yam starch

\begin{tabular}{|c|c|c|c|c|c|c|c|c|}
\hline Sample & $\begin{array}{l}\text { Peak Viscosity } \\
\text { PV (RVU) }\end{array}$ & $\begin{array}{l}\text { Trough } \\
\text { Viscosity } \\
\text { TV(RVU) }\end{array}$ & $\begin{array}{l}\text { Breakdown } \\
\text { Viscosity } \\
\text { BV(RVU) }\end{array}$ & $\begin{array}{l}\text { Final Viscosity } \\
\text { FV(RVU) }\end{array}$ & $\begin{array}{l}\text { Setback Viscosity } \\
\text { SV(RVU) }\end{array}$ & $\begin{array}{l}\text { Peak } \\
\text { Time(mins) }\end{array}$ & $\begin{array}{l}\text { Pasting } \\
\text { Temperature } \\
\left({ }^{\circ} \mathrm{C}\right)\end{array}$ & $\begin{array}{l}\text { Breakdown } \\
\text { Ratio }\end{array}$ \\
\hline Native & $583.63 \pm 15.03$ & $508.96 \pm 13.49$ & $74.67 \pm 1.53$ & $811.63 \pm 7.37$ & $302.67 \pm 6.13$ & $5.6 \pm 0.0$ & $84 \pm 1.13$ & 0.87 (MST) \\
\hline $4 \%$ HPS & $454.54 \pm 7.48$ & $410 \pm 3.42$ & $44.54 \pm 4.07$ & $750.67 \pm 8.37$ & $340.67 \pm 4.95$ & $5.53 \pm 0.0$ & $84.1 \pm 0.0$ & $0.90(\mathrm{SST})$ \\
\hline $6 \%$ HPS & $297.83 \pm 11.55$ & $284.54 \pm 10.90$ & $13.29 \pm 0.65$ & $466.38 \pm 11.61$ & $181.83 \pm 0.71$ & $7 \pm 0.0$ & $86.4 \pm 0.1$ & $0.96(\mathrm{SST})$ \\
\hline $8 \%$ HPS & $571.17 \pm 2.83$ & $258.42 \pm 0.71$ & $97.67 \pm 2.12$ & $303.92 \pm 7.07$ & $45.5 \pm 6.36$ & $4.46 \pm 0.0$ & $79.5 \pm 0.6$ & 0.45 (HST) \\
\hline $10 \%$ HPS & $450.921 \pm 10.14$ & $352.83 \pm 1.53$ & $97.67 \pm 8.01$ & $483.71 \pm 3.36$ & $130.46 \pm 1.24$ & $5 \pm 0.1$ & $81.95 \pm 0.6$ & $0.78(\mathrm{MST})$ \\
\hline $12 \%$ HPS & $505.29 \pm 9.02$ & $389.63 \pm 13.73$ & $115.67 \pm 4.71$ & $578.17 \pm 1.53$ & $188.5417 \pm 12.20$ & $5.13 \pm 0.1$ & $81.93 \pm 0.6$ & 0.77 (MST) \\
\hline
\end{tabular}

Means in columns are significantly different at $5 \%$ level $(\mathrm{P}<0.05)$. HST-highly shear thinning, $(\mathrm{BDR}<0.5)$, MST-moderately shear thinning (BDR of 0.5-0.8), SST-slightly shear thinning (BDR OF 0.8-1.0). 


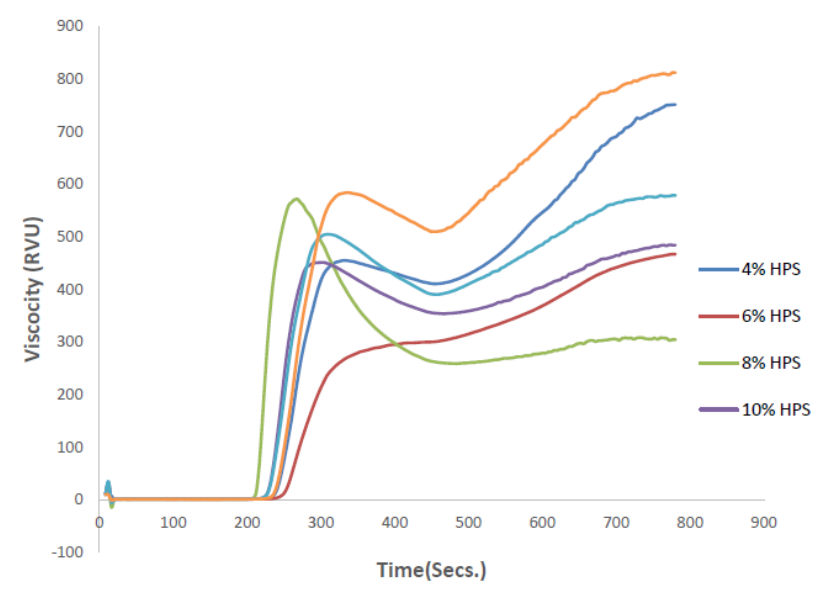

Figure 3. Pasting profile of native and hydroxypropylated water yam starch

\subsubsection{Freeze Thaw Stability (FTS) of Native and Hydroxypropylated Water Yam Starch}

Percentage syneresis increased progressively as the number of freeze thaw cycles rose during which native starch gel (spongylike in texture) exuded a lot of water (Figure 4). Comparatively, the gels from hydroxypropylated water yam starches were soft and elastic, discharging less water. Noteworthy is the fact that syneresis was not observed in hydroxypropylated starch until the third cycle for 4-6\%HPS (syneresis of $4.28 \%$ and 3.39\% respectively) and fourth cycle for $8-12 \%$ HPS $(1.09 \%, 1.30 \%$ and $1.13 \%$ respectively). Also, syneresis apparently reduced as the MS of the hydroxypropylated starches increased with the greatest reduction being at $8 \%$ HPS. The amount of water exuded by the frozen starches differed significantly $(\mathrm{P} \leq 0.05)$. This is similar to what was established from the hydroxypropylation of finger millet (Lawal, 2009) and syneresis where in the former became higher with storage duration (Lawal, 2008). Syneresis in freeze-thawed gels is attributed to the increase of molecular association between starch chains at reduced temperature, exuding water from the gel structure. This compares favourably with the observation by Afolabi \& Owolabi (2005) on hydrothermal treatment of finger millet starch. They noted a rise in hydrophilic and hydrophobic tendencies with increasing level of hydrothermal treatment while acid and enzymatic modifications culminated in decrease in syneresis (Lawal, 2009). The Drastic reduction in diminished syneresis following modification could also be attributed to the impediment of inter-chain bonding between the starch molecules by the incorporated hydroxypropyl groups. In addition, the hydrophilic nature of the hydroxypropyl groups enhanced water-holding ability of the starch pastes, thereby limiting the amount of water exuded. Schmitz et al., (2005) came to a similar conclusion during which in the hydroxypropylation of cassava starch during which the lowest loss of water in the freezing-thawing cycles was obtained.. Hydroxypropylation effectively retards the gelling and retrogradation tendencies of starch gels, increases water holding capacity, and improves the freeze-thaw stability or cold storage stability (Hoover et al., 1988; Liu et al., 1999). Freeze-thaw stability expressed as percentage syneresis is also used as an indicator of starch retrogradation.Retrogradation property is a fundamental characteristic of starch utilisation in the food industry, where it is used as a thickening agent in sauces, allowing for unaltered transparency during storage (Schmitz, 2004).When starch gel is stored for a long time under refrigerated or frozen conditions, there is a gradual increase in rigidity as crystallites begin to form, and phase separation between polymer and solvent occurs. Considering the amount of water released in all the cycles, gels from 8-12\%HPS exhibited lowest tendency to syneresis compared to 4-6\%HPS and native starches. This result indicates that hydroxypropylated starch at high concentration of propylene oxide (8-12\%HPS) is more stable to freeze-thawing than lower concentration (4-6\%HPS) and hence would be better suited for use in frozen products than others (Mweta et. al., 2008). This is in agreement with the findings of Lee \& Yoo, (2011) who reported that increase in propylene oxide during hydroxypropylation substantially improved the freeze-thaw stability of Saba banana starch.. The fall in syneresis for $8-12 \%$ HPS can be attributed to reduction in the inter chain bonding between the starch molecules (Lawal, 2009). Among all the starches, 8-12\%HPS would be most suitable as they presented the highest free-thaw stability 


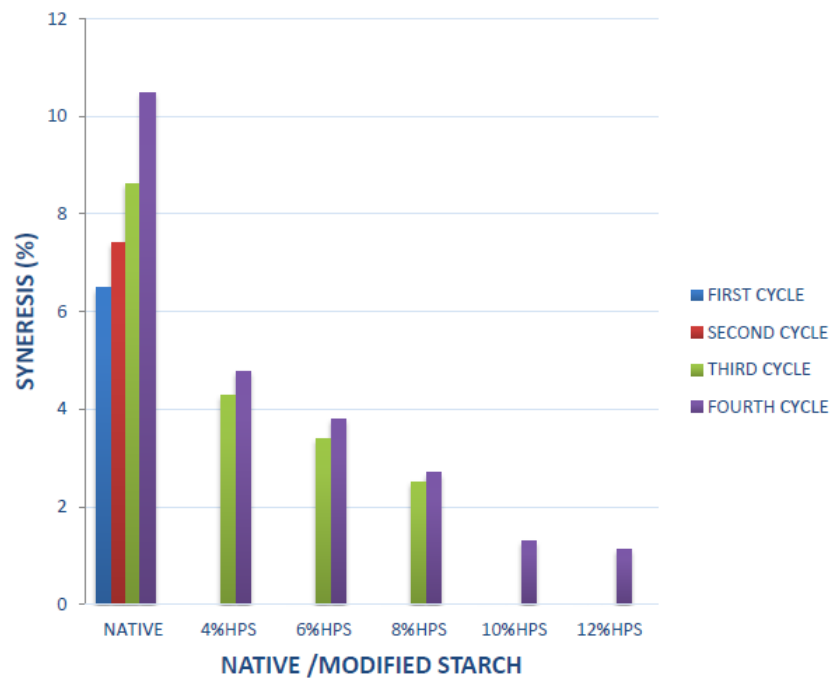

Figure 4. Freeze thaw stability of native and hydroxypropylated water yam starch

\subsubsection{Fourier Transforms Infrared (FTIR) Spectroscopy Analysis}

The FT-IR spectra of the native and hydroxypropylated yam starch indicated bands corresponding to the stretching of the principal groups. This compares favourably with the findings of some research works (Mano et al., 2003,Xu et al., 2007, Guerra et al., 2008).Among the FTIR spectra of hydroxypropyl starches, 12\%HPS showed a stronger peak band at $3645.7 \mathrm{~cm}^{-1}$ than the native and other hydroxypropylated starches.

The FTIR spectra of 4\%HPS had shown characteristic peaks between $3228.78-3645.7 \mathrm{~cm}_{-1}^{-1}$ indicating C-H aromatic stretch, $1645.58-1646 \mathrm{~cm}^{-1}$ (C=C stretch), 929.45-932.45 $-\mathrm{cm}^{-1}$ (C-H stretch), $2922 \mathrm{~cm}^{-1}$ (C-H aliphatic stretch). The observed absorption band at $1004-1155 \mathrm{~cm}^{-1}$, is a C-O stretch which indicates the presence of alkyl ethers group. it demonstrated the peak at around $1413 \mathrm{~cm}^{-1}$ as the $\mathrm{O}-\mathrm{H}$ bend (Mano et al., 2003).The FTIR spectra of all hydroxypropylated starch samples reflects the typical absorption of the starch backbone as well as the additional peaks. New peaks occurred at $1050.7 \mathrm{~cm}^{-1}$ and $1260 \mathrm{~cm}^{-1}$ indicating the substitution of alkyl ether group on the starch molecular chains. The frequency of $\mathrm{C}=\mathrm{O}$ is much lower from the value found for the parent carboxylic acid possibly due to the resonance effect. During the ionization, the formation of COO- group would exhibit resonance effect between the two $\mathrm{C}-\mathrm{O}$ bonds. Consequently, the characteristic carbonyl absorption vanished and are replaced by two bands $-1645 \mathrm{~cm}^{-1}$ and $1456 \mathrm{~cm}^{-1}$ and between $1413 \mathrm{~cm}^{-1}$ and $1301 \mathrm{~cm}^{-1}$, corresponding to the anti-symmetrical and symmetrical vibrations of the COO- structure. The FTIR spectra of water yam starch and hydroxypropyl starch was found at $1004 \mathrm{~cm}^{-1}$. The spectra also showed that the absorption at $1371.5 \mathrm{~cm}^{-1}$ could be due to the overlapping of $\mathrm{CH} 2$ and $\mathrm{O}-\mathrm{H}$ in-plane bending. The absorption band of $\mathrm{O}-\mathrm{H}$ stretching is reduced in intensity, shifting to $3645.7 \mathrm{~cm}^{-1}$. This shift in the $\mathrm{O}-\mathrm{H}$ group could be attributable to the interaction of $\mathrm{O}-\mathrm{H}$ group with the carboxylic group. The reduction in intensity of this band may also correspond to partly substituted $\mathrm{O}-\mathrm{H}$ group with the hydroxypropyl moeity during the etherification process. Fang et al., (2002) observed similar changes of the $\mathrm{O}-\mathrm{H}$ vibration during the modification of potato starches.

\section{Conclusion and Recommendation}

Generally, the results obtained in this work indicate that hydroxypropyl water yam starch has very good physicochemical, morphological and functional parameters that could be utilized and thereby position this under-utilized starch source for good starch market globally.

Extensive work can still be carried out on the degree of retrogradation, texture profile analysis (TPA) during storage of the water yam starch and gelatinisation using differential scanning calorimetry (DSC).Sorption isotherm behaviour of the starch to determine the safe storage temperature could also be determined and the concept of plasticization of water using nuclear magnetic resonance (NMR) spectroscopy. In addition, use of $\mathrm{x}$-ray diffractograms (XRD), scanning electron microscopy (SEM), for the native water yam starch to show the structure pattern of the starch and to determine the surface properties and crystallinity is also an additional knowledge to widen its food application. 


\section{References}

Abbey, B. W., \& Ibeh, G. O. (1988). Functional properties of raw and heat processed cowpea (Vigna unguiculata Walp) flour. Journal of Food Science, 53, 1775-1777. https://doi.org/10.1111/j.1365-2621.1988.tb07840.x

Adebowale, K.O., Henle, T., Schwarzenbolz, U., \& Doert, T. (2009). Modification and properties of African yam bean (Sphenostylis stenocarpa Hochst. Ex A. Rich.) Harms starch I: Heat moisture treatments and Annealing. Food Hydrocolloids, 23, 1947-1957. https://doi.org/10.1016/j.foodhyd.2009.01.002

Adebowale, K. O., Afolabi, T. A., \& Lawal, S. O. (2002). Isolation, chemical modification and physicochemical characterisation of Bambarra groundnut (Voandzeia subterranean) starch and flour. Food Chemistry, 78, 305-311. https://doi.org/10.1016/S0308-8146(02)00100-0

Adebowale, K. O., \& Lawal, O. S. (2003). Functional properties and retrogradation behaviour of native and chemically modified starch of mucuna bean (Mucuna pruriens). Journal of the Science of Food and Agriculture, 83, 1541-1546. https://doi.org/10.1002/jsfa.1569

Adebowale, K.O., Olu-Owolabi, B. I., Olayinka, O. O., \& Lawal, O. S. (2005). Effect of heat moisture treatment and annealing on physicochemical properties of red sorghum starch. African Journal of Biotechnology, 4(9), 928-933. https://doi.org/10.5897/AJB2005.000-3197

Akinoso, R., \& Abiodun, O. A. (2013). Effect of harvesting periods on the morphology and physico-chemical properties of trifoliate yam starches. Starch, 65, 753-61. https://doi.org/10.1002/star.201200171

Akubor, P. I. (2013). Effect of ascorbic acid and citric acid treatments on the functional and sensory properties of yam flour. International. Journal of agricultural policy and research, 1(4), 103-108.

Retrieved from http://www.journalissues.org/IJAPR/

Ali, N., Falade, K. O., \& Akingbala, J. O. (2012). Effect of cultivar on quality attributes of sweet potato fries and crisps. Food and Nutrition Sciences, 3, 224-232. https://doi.org/10.4236/fns.2012.32033

Amani, N. G., Kamenan, A., Rolland-Sabate, A., \& Colonna, P. (2005). Stability of yam starch gels during processing. African Journal of Biotechnology, 4(1), 94-101. https://doi.org/10.5897/AJB2005.000-3016

AOAC. (2000). Official Methods of Analysis of AOAC International. 17th Edn., AOAC International, Gaitherburg, MD., USA., ISBN-13: 9780935584677, Pages: 2200.

Aremu, M. O., Olonisakin, A; Atolaye, B. O., \& Ogbu, C. F. (2006). Some nutritional and functional studies of Prosopis africana. Electronic Journal of Environmental, Agricultural and Food Chemistry, 5(6), 1640-1648.

Awokoyaa, K. N., Nwokocha, L. M., Moronkolac, B. A., \& Moronkolaa, D. O. (2011). Studies on the isolation, structural and functional properties of Starch Succinate of Cocoyam (Colocasia antiquorum). Der Chemica Sinica, 6, 228-244

Baldwin, P. M. (2001). Starch granule-associated proteins and polypeptides: A review. Starch, 53, $475-503$. https://doi.org/10.1002/1521-379X(200110)53:10<475::AID-STAR475>3.0.CO;2-E

Bello-Perez, L. A., Agama-Acevedo, E., Sanchez-Hernandez, L., \& Paredes-Lopez, O. (1999). Isolation and partial characterization of banana starches. Journal of Agricultural and Food Chemistry, 47, 854-857. https://doi.org/10.1021/jf980828t

Berger, K. G. (1997). Ice cream. In: Friberg, S. E. \& Larsson, K. (eds.), 3rd Ed., Food Emulsions (pp. 413-490). Marcel Dekker, NY.

Betancur-Ancona, D., Lo'pez-Luna, J., \& Chel-Guerrero, L. (2003). Comparison of the chemical composition and functional properties of Phaseolus lunatus prime and tailingstarches. Food Chemistry, 82, 217-225. https://doi.org/10.1016/S0308-8146(02)00515-0

Bhattacharya, S., \& Prakash, M. (1994). Extrusion blends of rice and chicken pea flours: A response surface analysis. Journal of Food Engineering, 21, 315-330. https://doi.org/10.1016/0260-8774(94)90076-0

Blennow, A., Nielsen, T. H., Baunsgaard, L., Mikkelsen, R., \& Engelsen, S. B. (2002). Starch phosphorylation: a new front line in starch research. Trends in Plant Science, 7, 445-450.

https://doi.org/10.1016/S1360-1385(02)02332-4

Brunnschweiler, J., Luethi, D., Handschin, S., Farah, Z., Escher, F., \& Conde-petit, B. (2005). Isolation, Physicochemical Characterization and Application of Yam (Dioscorea spp.) Starch as Thickening and Gelling Agent. Starch/Stärke, 57, 07-117. https://doi.org/10.1002/star.200400327

Buleon, A., Colonna, P., Planchot, V., \& Ball, S. (1998). Starch granules: structure and biosynthesis. 
International journal of Biological Macromolecules, 23(2), 85-112. https://doi.org/10.1016/S0141-8130(98)00040-3.

Bultosa, G., Hall, A. N., \& Taylor, J. R. N. (2002). Physico-chemical characterization of grain tef (Eragrostis tef (zucc.) Trotter) starch. Starch/Starke. 54, 461-468. https://doi.org/10.1002/1521-379X(200210)54:10<461::AID-STAR461>3.0.CO;2-U

Collado, L. S., \& Corke, H. (1997), Properties of starch noodles as affected by Sweetpotato genotype. Cereal Chemistry, 74(2), 182-187. https://doi.org/10.1094/CCHEM.1997.74.2.182

Chatakanonda, P., Wansuksri, R., \& Sriroth, K. (2011). Impact of Annealing on Susceptibility to acid hydrolysis and physico-Chemical properties of Cassava starch. Kasetsart Journal (Nat.Sci.), 45, 284-294.

Chavan, U. D., Shinde, B. G., Kadam, S. S., \& Amarowicz, A. (2010). Isolation and Characterization of Starch from Horse Gram. African Journal of Food Science and Technology, 1(3), 64-67.

Chen, Z., Schols, H. A., \& Voragen, A. G. J. (2003). Physicochemical Properties of Starches Obtained from Three Varieties of Chinese Sweet Potatoes. Journal of Food Science, 68, 431-437. https://doi.org/10.1111/j.1365-2621.2003.tb05690.x

Choi, S. G., \& Kerr, W. L. (2003). Effects of chemical modification of wheat starch on molecular mobility as studied by pulsed 1H-NMR. Lebensmittel-Wissenchaft Und-Technologie, 51, 1-8. https://doi.org/10.1016/s0023-6438(02)00200-1

Chuenkamol, B., Puttanlek, C., Rungsardthong, V., \& Uttapap, D. (2007). Characterization of low-substituted hydroxypropylated canna starch. Food Hydrocolloids, 21, 1123-1132.

https://doi.org/10.1016/j.foodhyd.2006.08.013

Chung, H.-J., Lee, S.-Y., Kim, J.-H., Lee, J.-W., Byun, M.-W., \& Lim, S.-T. (2010). Pasting characteristics and in-vitro digestibility of $\gamma$-irradiated $\mathrm{RS}_{4}$ waxy maize starches. Journal of Cereal Science, 52, 53-58. https://doi.org/10.1016/j.jcs.2010.03.002

Dalaye, P. E., \& Techeira, E. (2009). Chemical and functional properties of native and modified yam (Dioscorea alata) starch. Interciencia, 34, 280-285.

Dias, F. F., Tekchandani, H. K., \& Mehta, D. (1997). Modified starches and their use by food industries. Indian Food Industry, 16, 33-39.

Ellis, R. P., Cochrane, P. M., Dale, F. M., Duffus C. M., Lynn, A., Morrison, I. M., .. Tiller, S. A. ( 1998). Starch production and industrial use. J. Sci. Food Agric., 77, 289-311. https://doi.org/10.1002/(SICI)1097-0010(199807)77:3<289::AID-JSFA38>3.0.CO;2-D

Emeje, M., Kaita, R., Isimi, C., Buragohain, A., Kunle, O., \& Ofoefule, S. (2012). Synthesis, physicochemical characterization, and functional properties of an esterified starch. African Journal of Food, Agriculture, Nutrition and Development, 65, 369-374.

Falade, K. O., \& Ayetigbo, O. E. (2015). Effects of physical and chemical modification on some physical, chemical, functional and pasting properties of starches of four yam (Dioscorea spp) cultivars. Food Hydrocolloids, 43, 529-539.

Fang, Y., Yang, S., \& Wu, G. (2002). Free radicals, antioxidants and nutrition. Nutrition, 18(10), 872-879. https://doi.org/10.1016/S0899-9007(02)00916-4

Food and Agriculture Organization (FAO) (1994). Tropical Root and Tuber Crops. In: Onwueme, I. C., \& Charles, W. B. (Eds.), Production, Perspectives and future Prospects. FAO Plant Production and Protection Paper 126, Rome, Italy.

Food and Agriculture Organization (FAO) (1998). Tropical starch misses the market. FAO Magazine. Retrieved from http://www.fao.org/ag/magazine/9809/spot3.htm

Gbenga, L. B., Olakunle, O., \& Adedayo, M. A. (2014). Influence of pregelatinization on the physicochemical and Compressional characteristics of starches obtained from two local varieties of Dioscorea Rotundata. IOSR Journal of Pharmacy, 4(6), 24-32. https://doi.org/10.9790/3013-040602024032

Gunaratne, A., \& Corke, H. (2007). Effect of hydroxypropylation and alkaline treatment in hydroxypropylation on some structural and physicochemical properties of heat-moisture treated wheat, potato and waxy maize starches. Carbohydrate Polymers, 68, 305-313. https://doi.org/ 10.1016/j.carbpol.2006.12.004

Gonnet, J. F. (1999). Colour effects of co-pigmentation of anthocyanins revisited - 2. A colorimetric look at the 
solutions of cyanin co-pigmented by rutin using the CIELAB scale. Food and Agriculture Organization of the United Nations. https://doi.org/10.1016/S0308-8146(99)00088-6

Han, X-Z., \& Hamaker, B. R. (2002). Partial leaching of granule-associated proteins from rice starch during alkaline extraction and subsequent gelatinization. Starch/Starke, 54, 454-460. https://doi.org/10.1002/1521-379X(200210)54:10<454::AID-STAR454>3.0.CO;2-M

Hung, P. V., \& Morita, N. (2005). Physicochemical properties of hydroxypropylated and cross-linked starches from A-type and B-type wheat starch granules-Review. Carbohydrate Polymers, 59, 239-246. https://doi.org/ 10.1016/j.carbpol.2004.09.016

Hoover, R. (2001). Composition, molecular structure, and physico-chemical properties tuber and root starches: A review. Carbohydrate. Polymers, 45, 253-267. https://doi.org/ 10.1016/S0144-8617(00)00260-5

Iheagwara, M. C. (2013). Isolation, Modification and Characterization of Sweet Potato (Ipomoea batatas L (Lam)) Starch. J Food Processing \& Technol., 4,198. https://doi.org/10.4172/2157-7110.1000198

Ihegwuagu, E. N., Omojola, O. M., Emeje, M. O., \& Kunle, O. O. (2009). Isolation and evaluation of some physicochemical properties of Parkia Biglobosa starch. Pure and Applied. Chem., 81(1), 97-104. https://doi.org/10.1351/PAC-CON-08-01-21

Isah, S., Oshodi, A. A., \& Atasie, V. N. (2015).Oxidation of acha (Digitaria exilis) starch using 3.5\% active chlorine sodium hypochlorite. Starch, 39, 284-288. https://doi.org/10.5897/AJPAC2015.0617

Joint FAO/WHO (2001). Expert Committee on Food Additives, In Compendium of Food Additive Specifications, Hydroxypropyl Starch, INS No. 1440. FAO Food and Nutrition Paper, 52, add. 9. Geneva. Retrieved from www.fao.org/3/a-i4144e.pdf

Jyothi, A. N., Rajasekharan, K. N., Moorthy, S. N., \& Sreekumar, J. (2005). Synthesis and characterization of low DS succinate derivatives of cassava (Manihot esculenta Crantz) starch. Starch/ Starke, 57, 319-324. https://doi.org/10.1002/star.200400374

Karim, A. A., Toon, L. C., Lee, V. P., Ong, W. Y., Fazilah, A., \& Noda, T. (2007). Effects of phosphorus contents on the gelatinization and retrogradation of potato starch. Journal of Food Science, 72(2), 132-138. https://doi.org/10.1111/j.1750-3841.2006.00251.x

Kaur, L., Singh, J., \& Singh, N. (2006). Effect of cross-linking on some properties of potato starches. Journal of the Science of Food and Agriculture, 86, 1945-1954. https://doi.org/10.1002/jsfa.2568

Kaur, L., Singh, N., \& Singh, J. (2004). Factors influencing the properties of hydroxypropylated potato starches. Carbohydrate Polymers, 55, 211-223. https://doi.org/10.1016/j.carbpol.2003.09.011

Krossmann, J. J., \& Lloyd, J. (2000). Understanding and influencing starch biochemistry Critical Reviews in Biochemistry and Molecular Biology, 35, 141-196.

Lai, L. N., Karim, A. A., Norziah, M. H., \& Seow, C. C. (2004). Effects of $\mathrm{Na}_{2} \mathrm{CO}_{3}$ and $\mathrm{NaOH}$ on pasting properties of selected native cereal starches. Journal of Food Science, 69, 249-256. https://doi.org/10.1111/j.1365-2621.2004.tb06324.x

Lawal, O. S. (2009). Starch hydroxyalkylation: Physicochemical properties and enzymatic digestibility of native and hydroxypropylated finger millet (Eleusine coracana) starch. Food Hydrocolloids, 23, 415-425. https://doi.org/10.1016/j.foodhyd.2008.02.013

Lawal, O. S., Adebowale, K. O., \& Oderinde, R. A. (2004). Functional Properties of amylopectin and amylose fractions isolated from Bambarra groundnut (Voandxeia subterranean) starch. African Journal of Biotechnology, 3, 399-404. http://dx.doi.org/10.5897/AJB2004.000-2082

Lawal, O. S., Adebowale, K. O., Ogunsanwo, B. M., Barba, L. L., \& Ilo, N. S. (2005).Oxidized and acid thinned starch derivatives of hybrid maize: functional characteristics, wide-angle X-ray diffractometry and thermal properties. International Journal of Biological Macromolecules, 35, 71-79. https://doi.org/10.1016/j.ijbiomac.2004.12.004

Lawal, O. S., Ogundiran, O. O., Awokoya, K., \& Ogunkunle, A.O. (2008). The low-substituted propylene oxide etherified plantain (Musa paradisiacal normalis) starch: Characterization and functional parameters. Carbohydrate Polymers, 74, 717-724. https://doi.org/ 10.1016/j.carbpol.2008.04.039

Lawal, O. S., Ogundiran, O. O., Adesogan, E. K., Ogunsanwo, B. M., \& Sosanwo, O. A. (2008b). Effect of hydroxypropylation on the properties of white yam (Dioscorea rotundata) starch. Starch, 60, 340-8. 
https://doi.org/10.1002/star.200700681

Lawal, O. S. (2009). Starch hydroxyalkylation: Physicochemical properties and enzymatic digestibility of native and hydroxypropylated finger millet (Eleusine coracana) starch. Food Hydrocolloids, 23, 415-425. https://doi.org/10.1016/j.foodhyd.2008.02.013

Lawal, O. S. (2008). Hydroxypropylation of pigeon pea (cajanus cajan) starch: preparation, functional characterizations and enzymatic digestibility. LWT - Food science and Technology, 44(3), 771-778 https://doi.org/10.1016/j.lwt.2010.05.025

Lee, H. L., \& Yoo, B. (2011). Effect of hydroxypropylation on physical and rheological properties of sweet potato starch. LWT- Food Science and Technology, 44(3), 765-770. https://doi.org/10.1016/j.lwt.2010.09.012

Lindeboom, N., Chang, P. R., \& Tylera, R. T. (2004). Analytical, biochemical and physicochemical aspects of starch granule size, with emphasis on small granules starches: A review. Starch, 56, 89-99. https://doi.org/10.1002/star.200300218

Liu, H. J., Ramsden, L., \& Corke, H. (1999). Physical properties and enzymatic digestibility of hydroxypropylated ae, wx, and normal maize starches. Carbohydrate Polymers, 40, 175-182. https://doi.org/10.1016/S0144-8617(99)00052-1

Mano, J. F., Koniarova, D., \& Reis, R. L. (2003). Thermal properties of thermoplastic starch/synthetic polymer blends with potential biomedical applicability. Journal of Materials Science, 14, 127-135. https://doi.org/10.1023/A:1022015712170

Marcon, M. J. A. (2004). Effect of traditional and modified fermentative processes on quality of sour cassava. $\mathrm{p}$ 118. Thesis, Federal University of Santa Catarina, Brazil: Department of Food Science and Technology.

Mojiono, J. F., Kusumawardani, S., Puspitasari, C., Maula, A., \& Purwandari, U. (2013). Annealed purple yam (Dioscorea alata var. purpurea) flour improved gelatinisation profile, but increased glycemic index of substituted bread. International Food Research Journal, 20(2), 865-871.

Moorthy, S. N. (2002). Physicochemical and functonal properties of tropical tuber starches: A review. Starch/Stärke, 54, 559-592. https://doi.org/10.1002/1521-379X(200212)54:12<559::AID-STAR2222559>3.0.CO;2-F

Morikawa, K., \& Nishinari, K. (2000). Effects of concentration dependence of retrogradation behaviour of dispersions for native and chemically modified potato starch. Food Hydrocolloids, 14, 395-401. https://doi.org/10.1016/S0268-005X(00)00021-7

Muazu, J., Musa, H., Isah, A. B., Bhatia, P. G., \& Tom, G. M. (2011). Extraction and characterization of Kaffir Potato Starch: A potential Source of pharmaceutical raw material. Journal of Natural Products and Plant Resources, 1(2), 41-49.

Mweta, D. E. (2009). Physicochemical, Functional and Structural Properties of Native Malawian Cocoyam and Sweetpotato Starches. PhD. Thesis, Dept. of chemistry and plant sciences, University of the Free State, Bloemfontein, SA. Pp 1-200.

Nadiha, M. Z., Fazilah, A., Bhat, R., \& Alias, K. A. (2010) Comparative susceptibilities of sago, potato and corn starches to alkali treatment. Food Chemistry, 121, 1053-1059. https://doi.org/10.1016/j.foodchem.2010.01.048

Naknaen, P. (2014). Physicochemical, thermal, pasting and microstructure properties of hydroxypropylated jackfruit seed starch prepared by etherification with propylene oxide. Springer Science, 9, 249-259. https://doi.org/10.1007/s11483-014-9347-2

Nuwamanya, E., Baguma, Y., Emmambux, N., Taylor, J., \& Patrick, R. (2010). Physicochemical and functional characteristics of cassava starch in Ugandan Varieties and their progenies. Journal of Plant Breeding and Crop Science, 2(1). 1-11. http://hdl.handle.net/2263/16845

Nwokocha, L. M., Aviara, N. A., Senan, C., \& Williams, P. A. (2009). A comparative study of some properties of cassava (Manihot esculenta, Crantz) and cocoyam (Colocasia esculenta, Linn) starches. Carbohydrate Polymers, 76(3), 362-367. https://doi.org/10.1016/j.carbpol.2008.10.034

Odeku, O. A., \& Picker-freyer, K. M. (2007). Analysis of the Material and Tablet Formation Properties of four Dioscorea Starches. Starch/Stärke, 59, 430-444. https://doi.org/ 10.1002/star.200700619 
Odeku, O., \& Picker-Freyer, K. (2009). Evaluation of the material and tablet formation properties of modified forms of Dioscorea starches. Drug development and industrial pharmacy, 35. 1389-406. https://doi.org/10.3109/03639040902960185

Oke, M. O., Awonorin, S. O., \& Workneh, T. S. (2013). Effect of varieties on physicochemical and pasting characteristics of Water yam flours and starches. African Journal of Biotechnology, 12(11), 1250-1256. https://doi.org/10.5897/AJB12.1666

Oladebeye, A. O., Oshodi, A. A., Amoo, I. A., \& Karim, A. A. (2013). Hydroxypropyl derivatives of legume starches: Functional, rheological and thermal properties. Starke, 65, 762-772. https://doi.org/10.1002/star.201300003

Olayinka, F. S., Olayinka, O. O., Olu-Owolabi, B. I., \& Adebowale, K. O. (2015). Effect of chemical modifications on thermal, rheological and morphological properties of yellow sorghum starch. Journal of Food Science and Technology - Mysore, 52(12), 1-7. https://doi.org/ 10.1007/s13197-015-1891-3

Olorunsola, E. O., Isah, A. B., \& Allagh, T. S. (2011). Effects of varying conditions of acid hydrolysis on some physicochemical properties of Ipomoea batatas starch. Nigerian. Journal of Pharmaceutical Sciences, 9(2), 73-80.

Omojola M. O., Akinkunmi Y. O., Olufunsho K. O., Egharevba H. O., \& Martins, E. O. (2010). Isolation and physico-chemical characterization of cola starch. African Journal of food, Agriculture, nutrition and development, 10(7), 2884-2900. https://doi.org/10.4314/ajfand.v10i7.59042

Onwuka, G. I. (2005). Food Analysis and Instrumentation: Theory and Practice. Lagos, Nigeria: Naphtali Prints.

Osundahunsi, O. F., Fagbemi, T. N., Kesselman, E., \& Shimoni, E. (2003). Comparison the physico-chemical properties and pasting characteristics of flour and starch from red and white sweetpotato cultivars. Journal of Agricultural and Food Chemistry, 51,2232-2236.

Otegbayo, B., Oguniyan, D., \& Akinwumi, O. (2014). Physicochemical and functional characterization of yam starch for potential industrial applications. Starch, 66, 235-50. https://doi.org/10.1002/star.201300056

P’erez, E., Gibert, O., Rolland-Sabat'e, A., Jim'enez, Y., S’anchez, T., Giraldo, A., ... Dufour, D. (2011). Physicochemical, Functional, and Macromolecular Properties of Waxy Yam Starches Discovered from -Mapueyll (Dioscoreatrifida) Geno types in the Venezuelan Amazon. J. Agric. Food Chem., 59(1), 263-273

Pal, J., Singhal, R. S., \& Kulkarni, P. R. (2000). A comparative account of conditions of synthesis of hydroxypropyl derivative from corn and amaranth starch. Carbohydrate Polymers, 43, 155-162. https://doi.org/10.1016/S0144-8617(00)00144-2

Pal, J., Singhal, P. S., \& Kulkarni, P. R. (2002). Physicochemical properties of hydroxypropyl derivative from corn and amaranth starch. Carbohydrate. Polymers, 48, 49-53. https://doi.org/10.1016/S0144-8617(01)00209-0

Perera, C., \& Hoover, R. (1999). Influence of hydroxypropylation on retrogradation properties of native, defatted and heat-moisture treated potato starches. Food Chemistry, 64, 361-375. https://doi.org/10.1016/S0308-8146(98)00130-7

Peroni, F. H. G., Rocha, T. S., \& Franco, C. M. L. (2006). Some structural and physicochemical characteristics of tuber and root starches. International Journal of Food Science and Technology, 12(6), 505-513. https://doi.org/10.1177/1082013206073045

Rahman, M. A., Nahar, N., Jabbar, M. A., \& Mosihuzzaman, M. (1999). Variation of carbohydrate composition of two forms of fruit from jack tree (Artacarpus heterophyllus) with different maturity and climatic conditions. Food Chemistry, 65, 91-97.

Rahman, M. A., Nahar, N., Jabbar, M. A., \& Mosihuzzaman, M. (1999). Variation of carbohydrate composition of two forms of fruit from jack tree (Artacarpus heterophyllus) with different maturity and climatic conditions. Food Chemistry, 65, 91-97. https://doi.org/10.1016/S0308-8146(98)00175-7

Ratnayake, W. S., Hoover, R., \& Warkentin, T. (2002). Pea starch: composition, structure and properties - a review, Starch/Stärke, 54(6), 217-234. https://doi.org/10.1002/1521-379X(200206)54:6<217::AID-STAR217>3.0.CO;2-R

Reddy, I., \& Seib, P. A. (2000). Modified waxy wheat starch compared to modified waxy corn starch. Journal of Cereal Science, 31, 25-39. https://doi.org/10.1006/jcrs.1999.0277 
Riley, C. K., Adebayo, S. A., Wheatley, A. O., \& Asemota, H. N. (2008). The interplay between yam (Dioscorea spp.) starch botanical source, micromeritics and functionality in paracetamol granules for reconstitution. European journal of pharmaceutics and biopharmaceutics, 70, 326-334. https://doi.org/10.1016/j.ejpb.2008.03.001

Rugchati, O., \& Tthanacharoenchanaphas, K. (2010). Comparison in some characteristics of Yam tubers starch (Dioscorea. spp) from Thailand. International Journal of Enviromental and rural development. 1-2.

Sanguanpong, V. (2003). Hydration and physico-chemical properties of small-particle cassava starch. $J$. of the Sci. of Food and Agriculture, 83(2), 123-132. https://doi.org/10.1002/jsfa.1285

Seetharaman, K., Tziotis, A., Borras, F., White, P. J., Ferrer, M., \& Robutti, J. (2001).Thermal and functional characterization of starch from Argentinean corn. Cereal Chemistry, 78, 379-386. https://doi.org/10.1094/CCHEM.2001.78.4.379

Senanayake, S., Gunaratne, A., Ranaweera, K. K. D. S., \& Bamunuarachchi, A. (2014). Effect of Hydroxypropylation on Functional Properties of Different Cultivars of Sweet Potato Starch in Sri Lanka. International Journal of Food Science. https://doi.org/10.1155/2014/148982

Schmitz, C. S. (2004). Characterisation and comparison of properties of dihydroxypropyl starch (DHPS) and hydroxypropylstarch (HPS) from cassava starch, native cassava and corn starch. Thesis, Federal University of Santa Catarina, Brazil: Department of Food Science and Technology.

Schmitz, C. S., De Simas, K. N., Santos, K., Joao, J. J., Amboni, D. de M. C., \& Amante, E. R. (2005). Cassava starch functional properties by etherification -Hydroxypropylation. International Journal of Food Science and Technology, 41, 681-687. https://doi.org/10.1111/j.1365-2621.2005.01136.x

Schmitz, C. S., de Simas, K. N., Santos, K., João, J. J., de Mello, C. A. R. D., \& Amante, E. R. (2006). Cassava starch functional properties by etherification-hydroxypropylation. International Journal of Food Science and Technology, 41:681-687. https://doi.org/10.1111/j.1365-2621.2005.01136.x

Shi, X., \& BeMiller, J. N. (2000). Effect of sulphate and citrate salts on derivatization of amylose and amylopectin during hydroxypropylation of corn starch. Carbohydrate Polymer, 43, 333-336. https://doi.org/10.1016/S0144-8617(00)00176-4

Shi, X., \& BeMiller, J. N. (2002). Aqueous leaching of derivatized amylose from hydroxypropylated common corn starch granules. Starch/Starke, 54, 16-19. https://doi.org/10.1002/1521-379X(200201)54:1<16::AID-STAR16>3.0.CO;2-P

Shimelis, A. E., Meaza, M., \& Rakshit, S. (2006). Physico-chemical Properties, Pasting Behavior and Functional Characteristics of Flours and Starches from Improved Bean (Phaseolus vulgaris L.) Varieties Grown in East Africa. Agricultural Engineering International: the CIGR Ejournal. Manuscript FP 05 015, 8, 18-36.

Singh, J., McCarthy, O. J., \& Singh, H. (2006). Physico-chemical and morphological characteristics of New ZealandTaewa (Maori potato) starches. Carbohydrate. Polymers, 64, 569-581. https://doi.org/10.1016/j.carbpol.2005.11.013

Singh, J., Kaur, L., \& McCarthy, O. J. (2007). Factors influencing the physicchemical ,morphological, thermal and rheological properties of some chemically modified starches for food applications-A review. Food Hydrocolloids, 21, 1-22. https://doi.org/10.1016/j.foodhyd.2006.02.006

Singh, J., \& Kaur, L. (2009). Advances in Potato chemistry and technology. 1st ed. Academic press, USA. pp. 273-318.

Singh, N., Chawla, D., \& Singh, J. (2004a). Influence of acetic anhydride on physicochemical, morphological and thermal properties of corn and potato starch. Food Chemistry, 86, 601-608. https://doi.org/10.1016/j.foodchem.2003.10.008

Singh, N., Singh, J., Kaur, L., Sodhi, N. S., \& Gill, B. S. (2003). Morphological, thermal and rheological properties of starches from different botanical sources. Food Chemistry, 81, 219-231. https://doi.org/10.1016/S0308-8146(02)00416-8

Srichuwong, S., Sunarti, T. C., Mishima, T., Isono, N., \& Hisamatsu, M. (2005). Starches from different botanical sources II: Contribution of starch structure to swelling and pasting properties. Carbohydrate Polymers, 62, 25-34. https://doi.org/10.1016/j.carbpol.2005.07.003

Srichuwong, S., \& Jane, J. L. (2007). Physicochemical properties of starch affected by molecular composition and structures: A review. Food Science and Biotechnology, 16, 663-74. 
Takizawa, F. F., Oliveira, da S. G., Eneias, K. F., \& Mottin, D. I. (2004). Characterization of Tropical Starches Modified with Potassium Permanganate and Lactic Acid. Brazilian archives of biology and technology: An International Journal, 47(6), 921-931. http://dx.doi.org/10.1590/S1516-89132004000600012

Tester, R. F., \& Morrison, W. R. (1990). Swelling and gelatinization of cereal starches. Cereal Chemistry, 67, 558-563.

Tester, R., \& Morrison, W. R. (1990a). Swelling and gelatinization of cereal starches: I. Effects of amylopectin, amylose, and lipids. Cereal Chemistry, 67, 551-557

Tetchi, F. A., Amani, N. G., \& Kamenan, A. (2007b). Contribution to light transmittance modelling in starch. African Journal of Biotechnology, 6(5), 569-575. https://doi.org/10.5897/AJB2007.000-2049

Tetchi, F. A., Dje, K. M., Dabonne, S., \& Kouame, L. P. (2012). Morphological Characteristics of Starch Granules from Yam Tuber Parts of "Florido" and "Bètè-Bètè" Cultivars (Dioscorea alata) during the Post-harvest Storage. Pakistan Journal of Nutrition, 11(1), 66-77. https://doi.org/10.3923/pjn.2012.66.77

Ubbor, S. C., \& Akobundu, E. N. T. (2009). Quality Characteristics of Cookies from Composite Flours of Watermelon Seed, Cassava and Wheat. Pakistan Journal of Nutrition, 8(7), 1097-1102. https://doi.org/10.3923/pjn.2009.1097.1102

Ukpabi, U. J. (2010). Farmstead bread making potential of lesser yam (Dioscorea esculenta) flour in Nigeria. Australian Journal of Crop Science, 4(2), 68-73

Vaclavik, V. A., \& Christian, E. W. (2008). Starches in Food. In: Essentials of Food Science. D. R. Heldman (Ed.). Springerlink, New York, USA, pp. 49-67.

Verwimp, T., Vandeputte, G. E., Marrant, K., \& Delcour, J. A. (2004). Isolation and Characterisation of Rye Starch. Journal of Cereal Science, 39, 85-90. https://doi.org/ 10.1016/S0733-5210(03)00068-7

Vorwerg, W., Dijksterhuis, J., Borghuis, J., \& Kro"ger, A. (2004). Film properties of hydroxypropyl starch. Starch, 56, 297-306. https://doi.org/10.1002/star.200300244

Waliszewski, K. N., Aparicio, M. A., Bello, L. A., \& Monroy, J. A. (2003). Changes of banana starch by chemical and physical modification. Carbohydrate Polymers, 52, 237-242. https://doi.org/10.1016/s0144-8617(02)00270-9

Walter, W. M., Truong, V. D., Wiesenborn, D. P., \& Carvajal, P. (2000). Rheological and Physico-chemical Properties of starches from Moist and Dry-type Sweet potatoes. J. Agric. Food Chemistry, 48, 2937-2942. https://doi.org/10.1021/jf9909631

Wang, L., \& Wang, Y. J. (2001). Structures and physico-chemical properties of acid-thinned corn, potato and rice starches. Starch, 53, 570-576. https://doi.org/10.1002/1521-379X(200111)53:11<570::AID-STAR570>3.0.CO;2-S

Wickramasinghe, H. A. M., Takigawa, S., Matsuura-Endo, C., Yamauchi, H., \& Noda, T. (2009). Comparative analysis of starch properties of different root and tuber crops of Sri Lanka. Food Chemistry, 112, 98-103. https://doi.org/ 10.1016/j.foodchem.2008.05.046

Xu Y., Miladinov, V., \& Hanna, M. A. (2004). Synthesis and characterization of starch acetates with high substitution. Cereal Chemistry, 81, 735-740. https://doi.org/10.1094/CCHEM.2004.81.6.735

Yaacob, B., Mohd, C. I. M. A., Kamaruddin, H., \& Bukhori, A. B. (2011). Optimization of Reaction Conditions for Carboxymethylated Sago Starch. Iranian Polymer Journal (English Edition), 20, 195-204

Yu, Y. T., Lu, T. L., Chiang, M. T., \& Chiang, W. (2005). Physicochemical properties of water soluble polysaccharide enriched fractions of adlay and their hypolipidemic effect in hamsters. Journal of Food and Drug Analysis., 13(4), 361-367.

Zaidul, I. S. M., Karim, A. A., Manan, D. M. A., Norulaini, N. A. N., \& Omar, A. K. M. (2003). Gelatinization properties of sago and wheat flour mixtures. ASEAN Food Journal, 12, 585-598.

Zhang, T., \& Oates, C. G. (1999). Relationship between amylase degradation and physicochemical properties of sweet potato starches. Food Chemistry, 65, 157-163. https://doi.org/10.1016/S0308-8146(98)00024-7

Zuluaga, M-F., Baena, Y., Mora, C-E., \& PonceD'leon, L-F. (2007). Physicochemical Characterization and Application of Yam (Dioscorea cayenensis-rotundata) Starch as a Pharmaceutical Excipient. Starch/Stärke, 59, 307-317. https://doi.org/10.1002/star.200600516 


\section{Copyrights}

Copyright for this article is retained by the author(s), with first publication rights granted to the journal.

This is an open-access article distributed under the terms and conditions of the Creative Commons Attribution license (http://creativecommons.org/licenses/by/4.0/). 